\title{
Earth rotation and geodynamics
}

\author{
Janusz Bogusz ${ }^{1}$, Aleksander Brzezinski ${ }^{2,4}$, Wieslaw Kosek ${ }^{3}$, Jolanta Nastula ${ }^{4}$ \\ ${ }^{1}$ Military University of Technology \\ Faculty of Civil Engineering and Geodesy \\ 2 Gen. S. Kaliskiego St., 00-908 Warsaw, Poland \\ e-mail: janusz.bogusz@wat.edu.pl \\ ${ }^{2}$ Warsaw University of Technology \\ Department of Geodesy and Geodetic Astronomy \\ 1 Pl. Politechniki., 00-661 Warsaw, Poland \\ e-mail: a.brzezinski@gik.pw.edu.pl \\ ${ }^{3}$ University of Agriculture in Krakow \\ Faculty of Environmental Engineering and Land Surveying \\ 24-28 Al. Mickiewicza, 30-059 Krakow, Poland \\ e-mail:kosek@cbk.waw.pl \\ ${ }^{4}$ Polish Academy of Sciences \\ Space Research Centre \\ 18A Bartycka St., 00-716 Warsaw, Poland \\ e-mail: nastula@cbk.waw.pl
}

Received: 7 April 2015 / Accepted: 24 May 2015

\begin{abstract}
This paper presents the summary of research activities carried out in Poland in 2011-2014 in the field of Earth rotation and geodynamics by several Polish research institutions. It contains a summary of works on Earth rotation, including evaluation and prediction of its parameters and analysis of the related excitation data as well as research on associated geodynamic phenomena such as geocentre motion, global sea level change and hydrological processes. The second part of the paper deals with monitoring of geodynamic phenomena. It contains analysis of geodynamic networks of local, and regional scale using space (GNSS and SLR) techniques, Earth tides monitoring with gravimeters and water-tube hydrostatic clinometer, and the determination of secular variation of the Earth' magnetic field.
\end{abstract}

Keywords: Earth rotation, GNSS, SLR, tidal investigations, Earth magnetic field

\section{Introduction}

The research concerning Earth rotation and geodynamics performed in Poland in a period of 2011-2014 was conducted mainly in the following research institutions, listed in an alphabetic order: Borowiec Astrogeodynamic Observatory, Space Research 
Centre of the Polish Academy of Sciences in Borowiec (BOR); Department of Applied Geomatics, Military University of Technology in Warsaw (MUT); Department of Geodesy, University of Agriculture in Krakow (UAK); Department of Geodesy and Geodetic Astronomy, Warsaw University of Technology (WUT); Department of Geodesy and Geodynamics, Institute of Geodesy and Cartography in Warsaw (IGiK); Department of Geodesy and Geoinformatics, Wroclaw University of Technology (PWr); Department of Photogrammetry and Remote Sensing, University of Warmia and Mazury in Olsztyn (UWM1); Department of Planetary Geodesy, Space Research Centre of the Polish Academy of Sciences in Warsaw (SRC); Department of Satellite Geodesy and Navigation, University of Warmia and Mazury in Olsztyn (UWM2); Institute of Geodesy and Geoinformatics, Wroclaw University of Environmental and Life Sciences (UPWr); Institute of Geography and Regional Development, University of Wroclaw (UWr); Polish Geological Institute - National Research Institute in Warsaw (PIG).

Earth rotation is considered as one of three pillars of modern geodesy, besides the geokinematics and gravity field. The Earth orientation parameters (EOP) which are determined on the regular basis from the observations of space geodesy techniques, are sensitive to the global mass and angular momentum exchanges between the solid Earth and its fluid envelopes, the atmosphere, the oceans, the land hydrosphere, the cryosphere and the core. Hence, the analysis of the observed EOP and of the related geophysical parameters is important for understanding the global processes in the system Earth. Modelling and predicting Earth orientation parameters are also essential for the realization of global reference systems, the International Terrestrial Reference System (ITRS) and the International Celestial Reference System (ICRS), and of relations between these systems (Rogowski and Brzezinski, 2012). The investigations on Earth rotation started in Poland in late 1970's. They were conducted mostly by the researchers of the SRC, concentrating on the theory and interpretation of the Earth rotation and geophysical excitation data. In the last years, several scientists from other research institutions (UAK, UWr, WUT) became involved in those investigations. Also the scope of research has been extended on the associated geodynamic phenomena, such as geocenter motion, global sea level change and hydrological processes.

Since 1980's the monitoring of the geodynamic phenomena became possible using space-based techniques. The models of the tectonic plate movement are described by means of the permanent station velocities. The results of research on velocities determined from Satellite Laser Ranging (SLR) as well as Global Positioning System (GPS) are presented in this review paper. The permanent observations were carried out on the EUREF Permanent Network (EPN), the ASG-EUPOS network, which a multifunctional active geodetic network in Poland, and on the geodynamic network in the Sudety Mts. (GEOSUD, S-W Poland), established in 1996 with some subsequent extensions. A very important element of geodynamic research concerns tidal observations. Such observations are carried out in Poland since early 1970's with spring gravimeters (gravimetric tides), horizontal pendulums and water tiltmeter (clinometric tides). Currently, tidal observations are carried out in two Polish observatories Borowa Gora (IGiK) and Ksiaz (SRC). Long-term research on secular variations of the 
geomagnetic field in Europe was continued at IGiK with the use of the geomagnetic data obtained from the European observatories.

\section{Earth rotation}

In a period of 2011-2014 investigations concerning Earth rotation have been carried out in Poland by the researchers of SRC, UAK, and WUT. Additional research on associated geodynamic phenomena, the geocentre motion, sea level change and modelling of hydrological processes, has been conducted at UAK and UWr. Polish researchers working on Earth rotation participated in the activities of the international scientific organizations (International Association of Geodesy - IAG, International Astronomical Union - IAU, International Earth Rotation and Reference Systems Service - IERS) and of their commissions and working groups. They were also active in the organization of national and international meetings devoted to the Earth rotation topics. Results of their research have been reported at the international conferences, workshops, and published in the scientific journals. Short summaries of the most important results and achievements together with the list of related publications are presented below.

\subsection{Theory of Earth rotation}

Modelling subdiurnal variations of Earth rotation: The diurnal and subdiurnal signals in Earth rotation despite the small size are important for understanding the high frequency global dynamics of the solid Earth and the overlying fluid layers. The research concerning such signals is also important for validation of the high resolution determinations of Earth orientation parameters and of the procedures applied for data reduction. The so-called complex demodulation (CD) technique applied by Brzezinski and his co-workers since the middle of 1990's, has been shown to be a powerful method for modelling subdiurnal signals in Earth rotation, particularly the irregular or quasi-harmonic variations which need to be monitored in the time domain and studied using the time domain methods. Complex demodulation is a method of extracting high frequency signals from time series. The output "image" of the signal is a low-frequency time series which is easy to handle in analysis (Fig. 1). Detailed description of the CD technique and its application for the Earth rotation studies was given by Brzezinski (2012). The paper begins with general introduction of the method and its properties, and then gives description of its application for modelling diurnal and subdiurnal components of polar motion and UT1, and of the corresponding excitation functions. Finally, the dynamical equations derived can be used for direct comparison of the signals demodulated from the Earth rotation to the geophysical excitation data.

A successful application of the $\mathrm{CD}$ technique for analysis of the Very Long Baseline Interferometry (VLBI) observations has been done in cooperation with researchers from the Institute of Geodesy and Geophysics of the Vienna University of Technology 

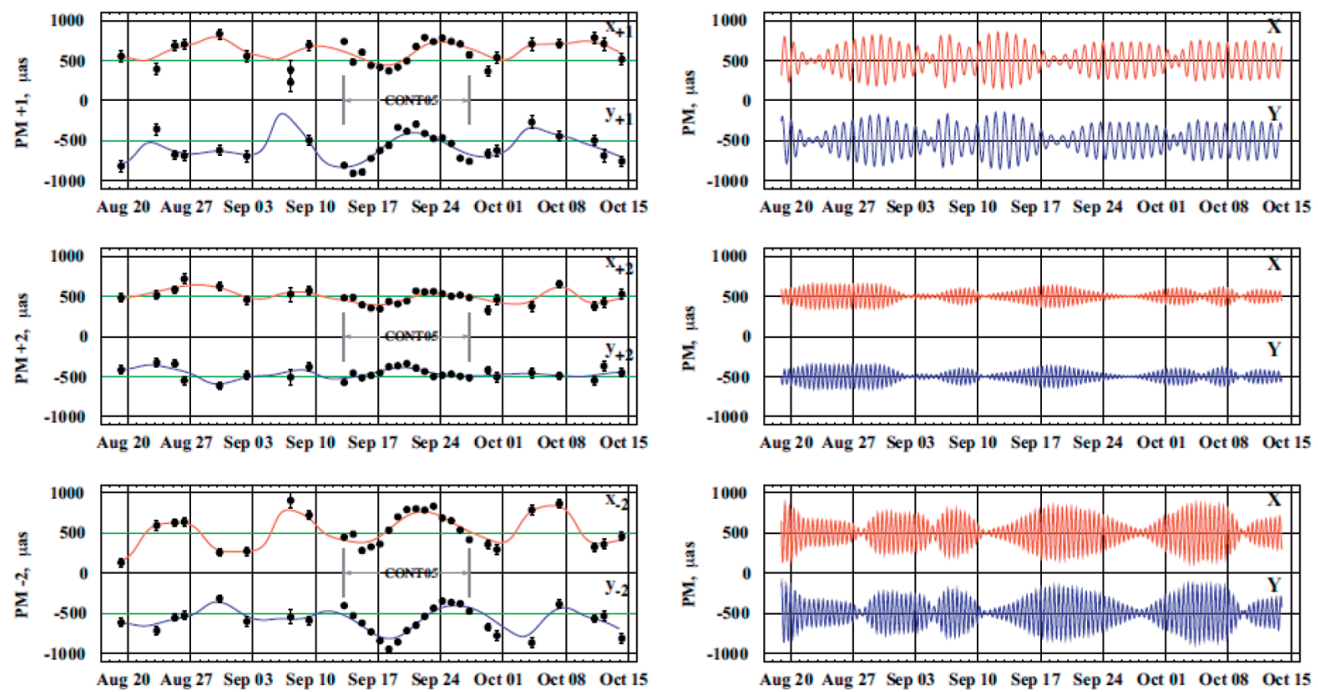

Fig. 1. From the top to bottom: prograde diurnal, prograde semidiurnal and retrograde semidiurnal components of polar motion (PM) demodulated from VLBI data. Shown are the raw estimates with error bars together with smoothed and interpolated curves (left), and the reconstructed corresponding highfrequency variations in PM (right). For the reason of visibility, the $x$ and $y$ components of demodulated and reconstructed series have been shifted in the vertical direction by adding $(x)$ or subtracting $(y)$ of 500 uas. Period of analysis 1984.0-2006.2, period shown 15 August - 15 October 2005 (Brzezinski, 2012)

(Böhm et al., 2012). The features of complex demodulation were used in an extended parameterization of polar motion and universal time which was implemented into a dedicated version of the Vienna VLBI Software VieVS. The functionality of the approach was evaluated by comparing the three sets of amplitudes and phases of harmonic variations at tidal periods (diurnal/semidiurnal): 1) derived from demodulated Earth rotation parameters (ERP; this is the subset of EOP including only polar motion components and UT1/LOD), 2) estimated from hourly resolved VLBI ERP time series and 3) taken from a recently published VLBI ERP model, to the terms of the conventional model for ocean tidal effects in Earth rotation recommended by the IERS. The three sets of tidal terms derived from VLBI observations extensively agree among each other within the $3 \sigma$ level of the demodulation approach, which is below 6 microarcseconds ( $\mu$ as) for polar motion and universal time. They also coincide in terms of differences to the IERS model, where significant deviations primarily for several major tidal terms are apparent. An additional spectral analysis of the demodulated ERP series of the ter- and quarterdiurnal frequency bands did not reveal any significant signal structure; see (Brzezinski and Böhm, 2012) for details. The CD technique applied in VLBI parameter estimation could be demonstrated a suitable procedure for the reliable reproduction of high frequency Earth rotation components and thus represents a qualified tool for future studies of irregular geophysical signals in ERP measured by space geodetic techniques. 
Nearly diurnal variations in the atmospheric and nontidal oceanic angular momenta (Atmospheric Angular Momentum - AAM, Oceanic Angular Momentum - OAM) contribute at measurable level to all components of Earth rotation. The estimated contributions to nutation have amplitudes over 0.1 milliarcsecond (mas), while in case of polar motion and UT1 the amplitudes are up to 0.04 mas. However, there are still significant discrepancies between the contributions estimated from different geophysical models as well as between those derived from geophysical models and geodetic data. Brzezinski (2011) used a new consistent set of 20-year time series of AAM and OAM based on the ERA-Interim reanalysis fields and the corresponding simulation from the ocean model for circulation and tides (OMCT), to extract the diurnal component and to estimate their influence on Earth rotation. The results were compared to the earlier estimates using the AAM series from the National Center for Environmental Prediction / National Center for Atmospheric Research (NCEP-NCAR) reanalysis model and the OAM series from the barotropic ocean model, derived by Brzezinski, Ponte and Ali in 2004. The estimated geophysical contributions were also compared to the available results derived from the space geodetic observations of Earth rotation.

Modelling free oscillations in Earth rotation: There are two important eigenmodes in the equatorial component of Earth rotation: the Chandler wobble $(\mathrm{CW})$ and the free core nutation (FCN). Studying rotational eigenmodes of the Earth is an important scientific task. First, their parameters, the resonant period $T$ and the quality factor $Q$, depend on the internal constitution of the planet and on its rheological properties. Second, by tracking the associated free motions of the pole one can gain much knowledge about global-scale processes taking place within the Earth and in its outer fluid layers. Finally, a good understanding of the eigenmodes is necessary for modelling and prediction of the time variations in polar motion and nutation.

The 14-months Chandler wobble is a free motion of the pole excited by geophysical processes. Several recent studies demonstrated that the combination of atmospheric and oceanic excitations contains enough power at the Chandler frequency and is significantly coherent with the observed free wobble. The paper (Brzezinski et al., 2011) was an extension of earlier studies by Brzezinski and co-authors using the same method of analysis but other available estimates of atmospheric and oceanic excitation of polar motion. The authors tried to assess the role of land hydrology in the excitation balance by taking into account the Hydrological Angular Momentum (HAM) estimates. The results obtained (Table 1) generally confirmed earlier conclusions concerning the atmospheric and oceanic excitation. Adding the hydrological excitation was found to increase slightly the $\mathrm{CW}$ excitation power, while the improvement of coherence depended on the geophysical models under consideration. The research on the free $\mathrm{CW}$ had been continued by Brzezinski and Rajner (2014) who estimated the CW parameters $T$ and $Q$ based on the stochastic models of polar motion and geophysical excitation data. They applied the Kalman deconvolution filter developed by Brzezinski in 1992. This filter can be used to analyse either the polar motion data alone, or simultaneously the polar motion and the excitation data, in order to estimate the unknown residual excitation. By imposing the minimum variance constraint upon the estimated unknown 
excitation they could find the best value of the resonant parameters $T$ and $Q$. The $\mathrm{CW}$ parameters estimated from different sets of polar motion and geophysical excitation data were compared to each other as well as to the earlier results derived by the alternative algorithms.

Table 1. Comparison of the observed (C04) and modelled (combination ECCO2: AAM - NCEP-NCAR reanalysis, OAM - data-assimilating model ECCO, kf066b run,

HAM - NCEP-water, time span 1993.0-2009.0) excitations of polar motion.

Complex correlation and coherence coefficients are shown as magnitude and argument, power spectral density (PSD) unit is mas $^{2} /$ cpy (Brzezinski et al., 2011)

\begin{tabular}{|l|c|c|c|}
\hline \multicolumn{1}{|c|}{$\begin{array}{c}\text { Geophysical } \\
\text { excitation vs. C04 }\end{array}$} & $\begin{array}{c}\text { Correlation } \\
\text { overall }\end{array}$ & $\begin{array}{c}\text { Coherence } \\
\text { at Chandler freq. }\end{array}$ & $\begin{array}{c}\text { PSD at Chandler } \\
\text { freq. mod./obs. }\end{array}$ \\
\hline A-pressIB & & & $6.9 / 42.6$ \\
A-wind & & & $3.1 / 42.6$ \\
A & $0.574-3^{\circ}$ & $0.66312^{\circ}$ & $11.9 / 42.6$ \\
O-mass & & & $10.4 / 42.6$ \\
O-motion & $0.847-4^{\circ}$ & $0.805-2^{\circ}$ & $3.6 / 42.6$ \\
A+O & & & $44.4 / 42.6$ \\
H & $0.842-5^{\circ}$ & $0.800-9^{\circ}$ & $3.0 / 42.6$ \\
A+O+H & & & $49.1 / 42.6$ \\
\hline
\end{tabular}

(Brzezinski et al., 2014) studied the excitation of the observed FCN signal by diurnal variation of the atmospheric and oceanic angular momenta, using AAM time series based on three different atmospheric reanalysis models, NCEP-NCAR, ERA-40, and ERAinterim, combined with OAM data from the ocean model OMCT. Comparison with the VLBI nutation data (Fig. 2) showed that the excitation based on the ERA-Interim model is not reliable at the diurnal retrograde frequencies. The spectral analysis of other excitation data sets confirmed the earlier conclusion that the mass term of excitation contains sufficient power to explain the observed amplitude of the FCN oscillation. The coherence analysis of geodetic and geophysical excitations was not conclusive, presumably because the signal-to-noise ratio in AAM and OAM data was too low in the vicinity of the FCN frequency.
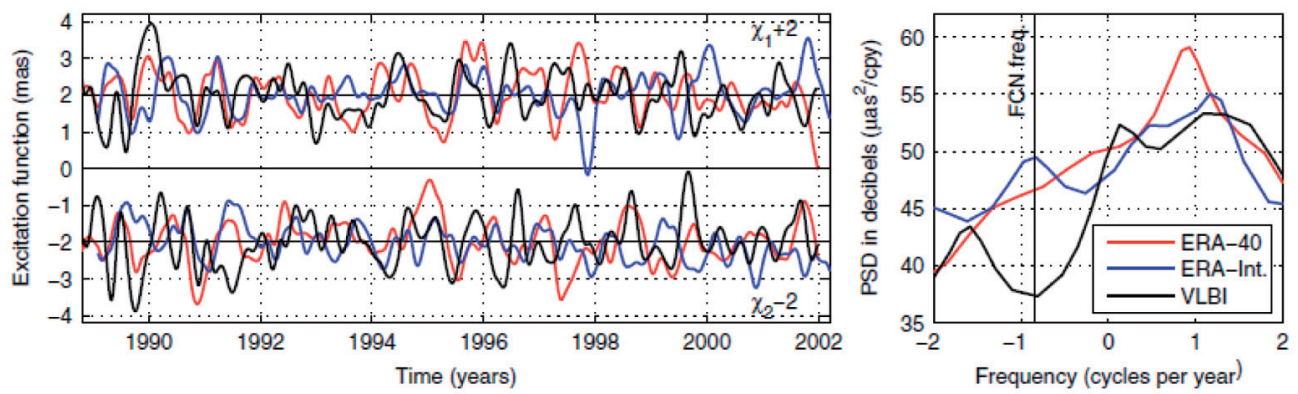

Fig. 2. Comparison of the geodetic excitation of nutation (black) to the combination of atmospheric and oceanic excitations, model ERA-40 (red) and ERA-interim (blue) (Brzezinski et al., 2014) 
Earth rotation observed by ring laser: The ring laser gyroscope (RLG) is a promising emerging technology for direct and continuously measured variations in Earth rotation. A single instrument is capable to determine the polar motion of the instantaneous rotation pole (IRP), in contrast to the space geodetic techniques which report the terrestrial motion of the conventional Celestial Intermediate Pole (CIP). Among several instruments which have been developed so far, the most accurate for monitoring high frequency polar motion is the $\mathrm{G}$ ring laser gyroscope in Wettzell, Germany. Considerable progress has been attained in the analysis and interpretation of the ring laser measurements recently. Brzezinski has been continued in a period of 2011-2014 his research on the interpretation of the RLG data (Tian et al., 2011).

\subsection{Analysis of polar motion observations and of the related excitation data}

Comparison of geophysical, gravimetric and geodetic excitations of polar motion: The contribution of Earth' hydrology to polar motion is usually evaluated from the continental water storage predicted by models. In order to validate their predictions, the modelled hydrological excitation can be compared to geodetic observations after removing atmospheric and oceanic effects. However, previous studies have shown large disagreements, mainly due to the lack of global measurements of related hydrological parameters. At present, it is possible to estimate the excitation functions of polar motion $\chi_{1}$ and $\chi_{2}$ due to the global hydrology from the observations of the Gravity Recovery and Climate Experiment (GRACE) mission. Data processing of GRACE observations has been carried out by several centres of analysis around the world. Seoane et al. (2011) focused on the GRACE solution computed by the Groupe de Recherche de Géodésie Spatiale (GRGS). The prominent annual variations observed by GRACE were in better agreement with geodetic observations than the models estimates (Fig. 3).

The main contribution to the annual signals came from the monsoon climates at the low latitudes regions (latitudes $<30^{\circ} \mathrm{N}$ ). Their influences on the annual oscillation estimated from the models and from the GRACE observations were in a very good agreement. The study showed that the effect of the high latitudes regions (latitudes $\geq 30^{\circ} \mathrm{N}$ ) can not be neglected. The principal areas of snow cover and continental climates were found at these latitudes. When comparing the contributions of the high latitudes regions predicted by the hydrological models to those observed by GRACE, the authors noticed the significant discrepancies, particularly at the annual band. At the inter-annual scales, GRACE observations confirmed the significant influence of the hydrology. Finally, the authors remarked that GRACE observations show the possible influence of water storage variation in exciting polar motion around the frequency of 3 cycles per year. They expected that improvements in the GRACE data processing and larger series of gravity field solutions would help the hydrological models to provide an adequate predictions and upgrade the global annual budget of the polar motion excitation.

Nastula et al. (2011a, 2011b) and Nastula (2014) compared contributions to polar motion excitation determined separately from each of three kinds of geophysical data: 

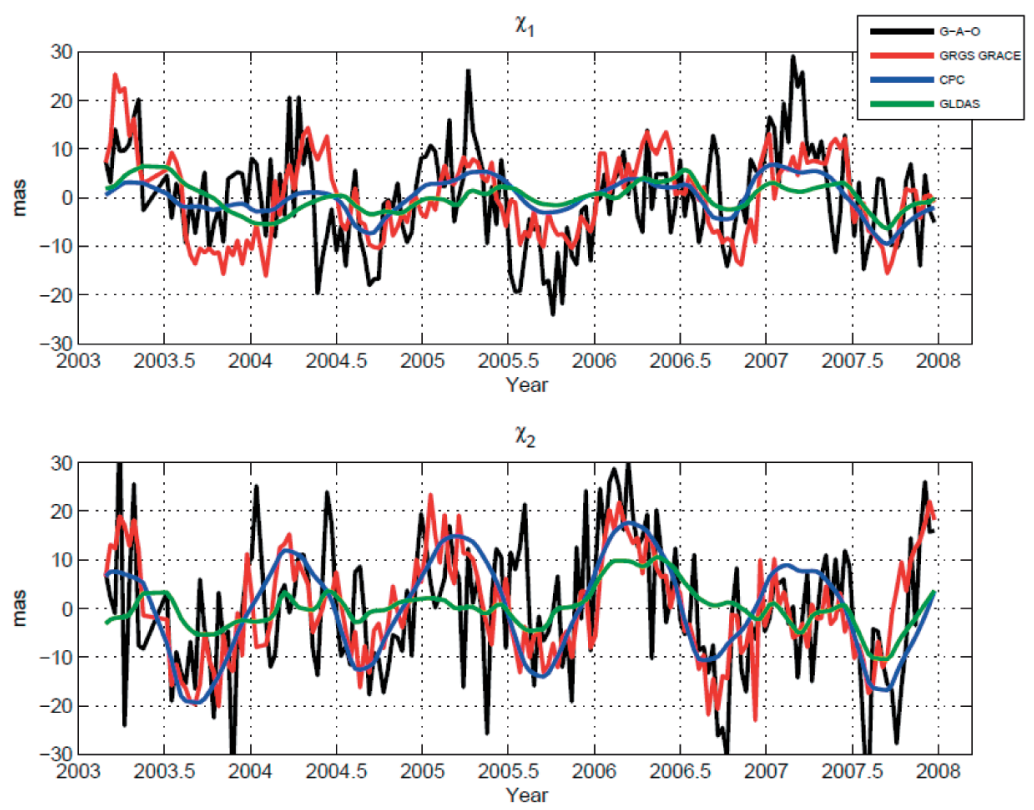

Fig. 3. Hydrological excitation functions computed from: geodetic observations (G-A-O), atmospheric and oceanic effects are removed; GRACE gravity field processed by GRGS; CPC hydrological model; and GLDAS hydrological model (Seoane et al., 2011)

atmospheric pressure, equivalent water height estimated from hydrological models, and harmonic coefficients of the Earth' gravity field obtained from GRACE experiment. Hydrological excitation function which is expressed by HAM, has been estimated from models of global hydrology, based on the observed distribution of surface water, snow, ice, and soil moisture. The authors used global models of land hydrosphere as well as of atmosphere and oceans, with the excitation of polar motion expressed by HAM, AAM and OAM, respectively. All those geophysical excitation functions were compared with the observed geodetic excitation function of polar motion (Geodetic Angular Momentum - GAM). The spectra and the time-variable spectra of the following excitation functions of polar motion: GAM, AAM+OAM, AAM+OAM+HAM, GAMAAM-OAM residual geodetic excitation function, and HAM were computed too. Phasor diagrams of the seasonal components of polar motion excitation functions, of all HAM functions as well as of two GRACE solutions: Center for Space Research (CSR), Centre National d'Etudes Spatiales / Groupe de Recherche de Géodésie Spatiale (CNES/GRGS) were determined. Results showed that different models of HAM differ significantly in amplitudes and phases. None of the HAM estimates closed the budget of the geophysical excitation of polar motion.

Analysis of the geodetic residuals: Differences between geodetic excitation function of polar motion GAM and joint atmospheric plus oceanic excitation functions (AAM, OAM) were computed (Nastula et al., 2011a; Kolaczek et al., 2012). The geodetic residuals 
computed for different models of AAM and OAM differ from one model to the other. Standard deviations of the geodetic residuals had maxima at the level exceeding a dozen mas. In the case of geodetic residuals computed with the same OAM models, differences were at the level of several mas. Comparison of geodetic residuals determined using different global ocean models showed significant differences among them. Comparison of these geodetic residuals and global hydrological and gravimetric excitation functions of polar motion showed that amplitudes of HAM variations are smaller than the variations of geodetic residuals. Therefore, the estimated time series of HAM have not enough energy to close the agreement between geodetic and geophysical excitations.

Regional excitation functions of polar motion: Nastula and Salstein (2012) estimated hydrological polar motion excitation functions over land areas regionally from hydrological models and from GRACE geopotential models. The hydrological models included equivalent water heights fields determined from groundwater, soil moisture and snow estimates on continents. They considered land data from the Climate Prediction Center (CPC) hydrological model and from the surface modelling system named Global Land Data Assimilation System (GLDAS), both providing monthly estimates. They also used satellite gravity data, expressed in terms of the GRACE RL04 Equivalent Water Thickness (EWT) from CSR. The mass effects of the ocean and the atmosphere as well as postglacial rebound were removed, so in this way hydrological excitation of polar motion could be estimated from the gravity data. Monthly resolution of the data restricted the analysis to seasonal signals only. Large hydrological variability in EWT occured in the lower latitude Southeast Asia, South Asia, and the South American Amazon regions; it remains significant in polar excitation even after multiplication by polar motion transfer functions, except the very low latitudes (Fig. 4). Differences between models and GRACErelated values were still considerable; they need to be reconciled to form the best estimates of hydrological variability. Additionally, variations from the atmosphere were determined over land areas from NCEP/NCAR reanalyses; they are noted to be strongly dependent on variability over the high topography regions of Eurasia and North America.

Regional values of the oceanic excitation functions of polar motion were computed from the bottom pressure and oceanic current fields from the ECCO/JPL dataassimilating model kf080 for the period 1993-2009 (Nastula et al., 2012). The influence of different geographic regions of the ocean on the excitation of polar motion determined by calculating correlations and covariances between these regional excitations and either the global non-atmospheric excitation or the global oceanic excitation. The nonatmospheric excitations estimated by subtracting the atmospheric signal from the excitation computed from geodetic observations of polar motion; the global oceanic excitation function is equivalent to the sum of the oceanic excitation function computed in every grid point. Using the oceanic bottom-pressure and current fields from the ECCO/JPL model kf080 the authors have explored the way in which different oceanic regions are responsible for non-atmospheric excitation of polar motion in two spectral bands, the annual and around the Chandler period. To quantify the relation between oceanic regional and global excitation functions, either geodetic non-atmospheric or 

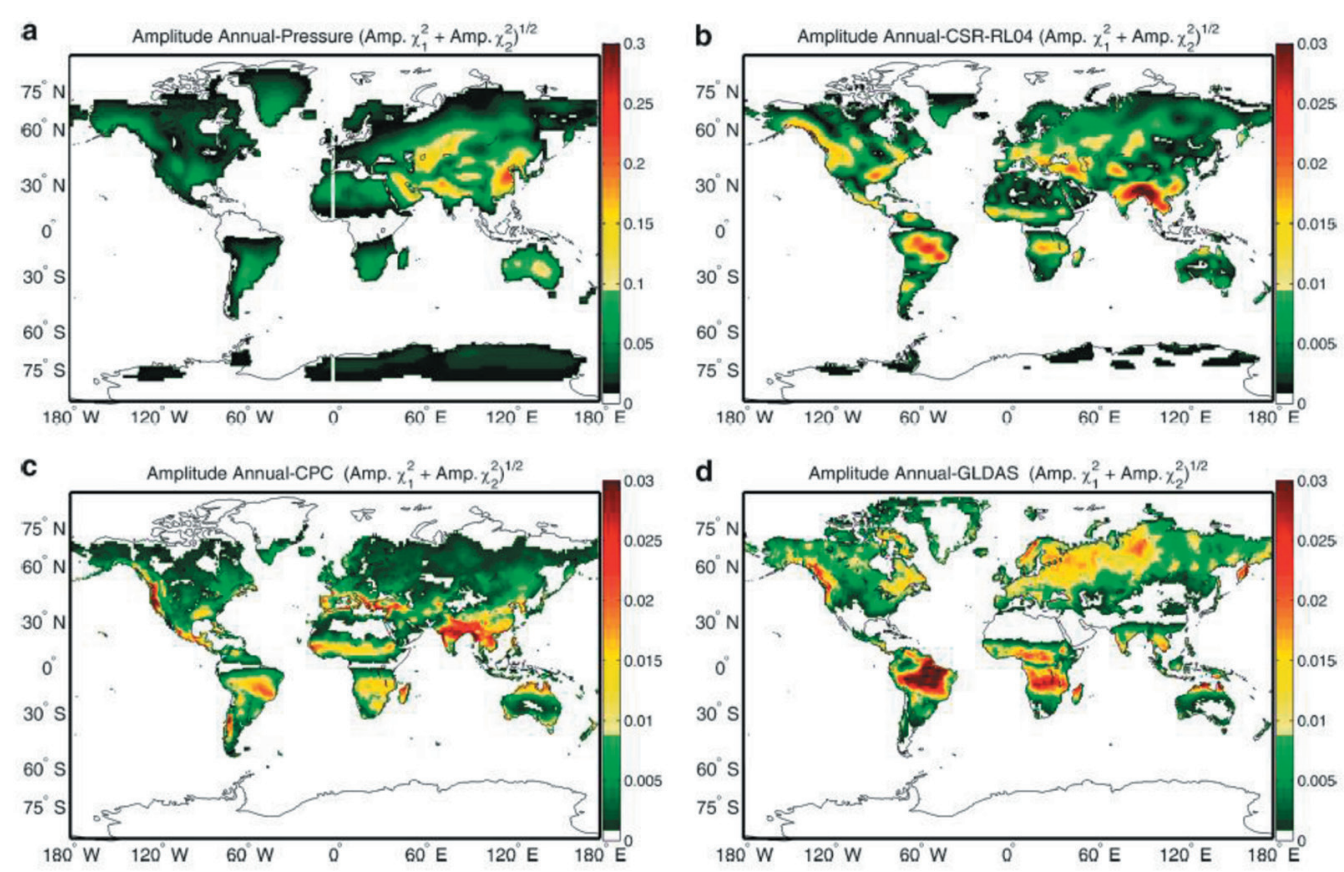

Fig. 4. Maps of amplitudes of the annual oscillation of complex-valued components of polar motion excitation functions: (a) atmospheric pressure polar motion excitation function, in $2.5^{\circ} \times 2.5^{\circ}$ grids; (b) gravimetric polar motion excitation function, from GRACE CSR RL04 solution in $1^{\circ} \times 1^{\circ}$ grids; from hydrological polar motion excitation function in $1^{\circ} \times 1^{\circ}$ grids from two models (c) CPC, (d) GLDAS (units - mas) (Nastula and Salstein, 2012)

oceanic, they computed covariance magnitude, coherence magnitude and phase shift between regional and global excitation values, using a Fourier transform band pass filter (FTBPF) applied to excitation functions expressed in terms of complex valued series $c=\chi_{1}+\mathrm{i} \chi_{2}$ (Fig. 5). The comparative analysis showed that the southern Indian Ocean and the South Pacific Ocean are important regions for non-atmospheric polar motion excitation. The maximum of variability over southern Indian Ocean was especially important in the case of the annual oscillation. The Atlantic Ocean makes less significant contribution to the non-atmospheric polar motion excitation than the Pacific and Indian Ocean in both spectral ranges considered. There is a high covariance of the signals generated over Inland seas like the Mediterranean and the Sea of Japan with the global signals.

Nastula et al. (2014) compared regional contributions to polar motion excitations determined separately from each of three kinds of geophysical data: atmospheric pressure, oceanic bottom pressure and land hydrology estimated from the GRACE satellite mission. Their key results of this fractional covariance study in the case of annual term were: (1) atmospheric pressure - strong variability over the high topography regions of Eurasia and North America, (2) ocean bottom pressure - strong variability in regions such as the southern Indian Ocean, (3) land hydrology - the prominent annual signals are situated in the Amazon, Central and South of Africa, North of Australia, 

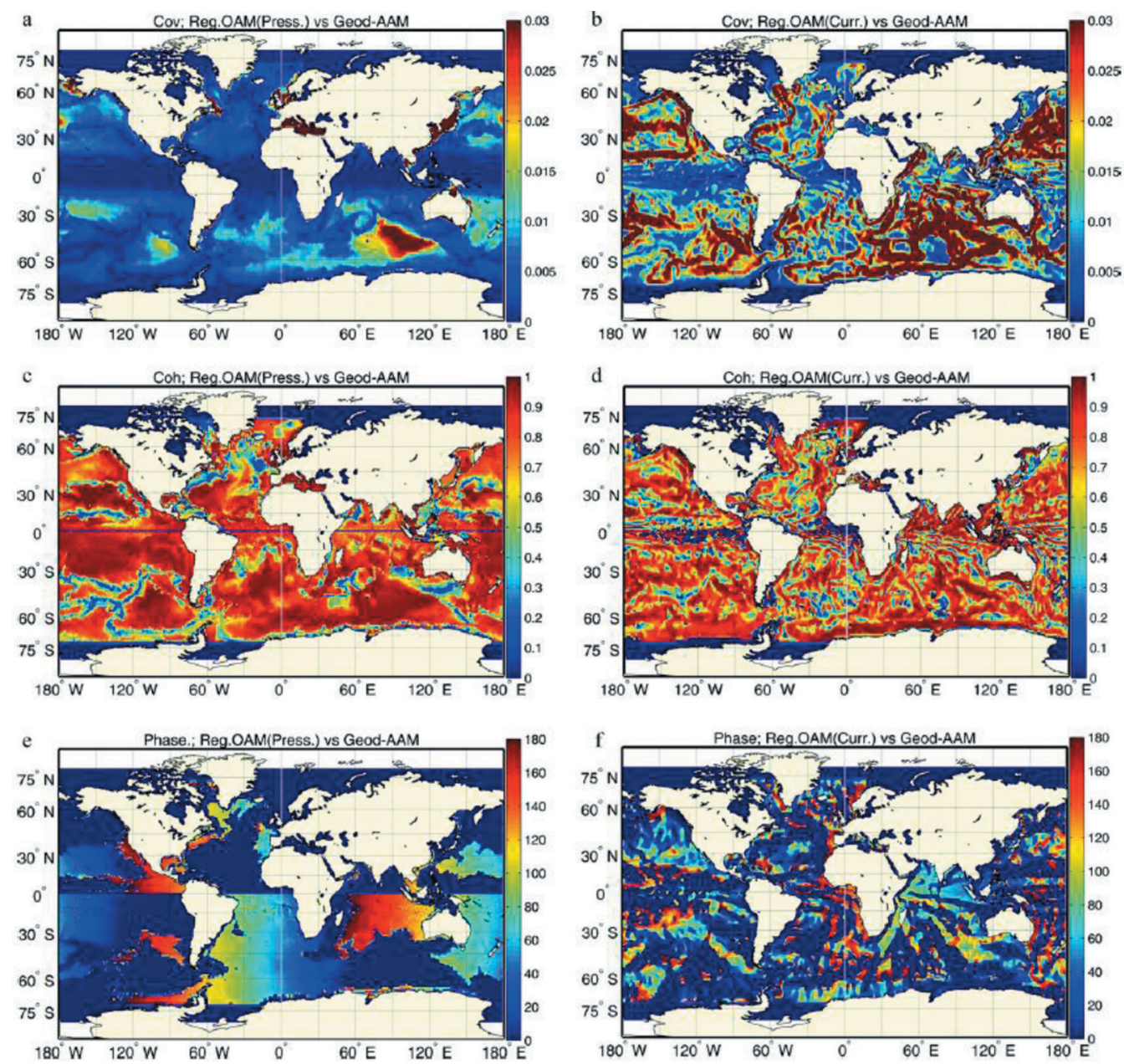

Fig. 5. Maps of $(a, b)$ magnitude of covariances, $(c, d)$ magnitude of coherence (e, f) and phase between prograde components of signals in the band around the Chandler oscillation of regional OAM (left panels pressure, right panels currents) and of global non-atmospheric geodetic excitation function

(Nastula et al., 2012)

India and Indochina. For the Chandler frequency band they found: (1) atmospheric pressure - two maxima in the variability one over the North European Plain, with the centre over the western side of the Central Russian Upland, and the other one over North Asia with the centre over Siberia and two secondary maxima, one over east coast of US and the other one south of the southern tip of South America, (2) ocean bottom pressure - south eastern Pacific, southern Indian Ocean, and North Atlantic dominate, (3) land - hydrology maxima were scattered above land areas.

Local Equivalent Water Thickness determination as a source of data for flood phenomenon observation: GRACE data was filtered and presented in the form of EWT with a temporal 
resolution of one month on $0.5^{\circ} \times 0.5^{\circ}$ grid for the whole territory of Poland (Birylo and Nastula, 2012b, 2012c). EWT on $0.5^{\circ} \times 0.5^{\circ}$ grid were determined from two global models of the land hydrosphere, WGHM and NOAA with temporal resolution of one month. EWT were then interpolated with linear interpolation method (Nearest Neighbour method) in four locations flood inundated in 2010 (Wilkow, Wroclaw, Wloclawek, Krakow). The biggest EWT changes occured in the southern Poland in March, and the lowest in the beginning of autumn. In addition, the results showed a significant increase of EWT in March 2010, and two, three times more than the average of EWT (0.06 $\mathrm{mm}$ ) in the months of flood 2010, i.e. in May and June 2010. In March, the average EWT in the southern Poland was about $0.06 \mathrm{~mm}$, while in 2010 it was twice larger. In the coming months, the EWT level felt usually to $0.02 \mathrm{~mm}$, and in 2010 , its state was $0.05 \mathrm{~mm}$. Based on analyses performed in the study, the authors concluded that the GRACE data could be used to test the feasibility of predicting flood events in Poland.

GRACE signal filtering: The effect of filtering the GRACE data on the estimated maps of EWT was analyzed (Birylo and Nastula, 2012a). The authors carried out four tests of filters, which included correlation, amplitude ratio and signal modification and EWT maps generation. The best results in the four tests were achieved when using ANS filter. Analysis of amplitude ratio showed that low degree harmonics of the gravity field lead to up to $28 \%$ reduction of the signal strength for the Gauss filter, and better results can be achieved by adapting longer filtering radius and inclusion harmonics of $118 \pm 10$ degree and order. The CNES/GRGS and Wiener-Kolmogorov filters indicated 6\% reduction of GRACE signal strength, and the ANS filter performed with $0 \%$ signal loss. The greatest signal modification was observed when using the Wiener-Kolomogorov filter $(0.06 \div 6.87)$, and the best results were obtained for the Gauss filter (even 0.00) the longer filtering radius, the more uniform modification. Using the CNES/GRGS filter led to modification rates of $0.02 \div 0.03$, and using the ANS filter it ranged from 0.18 to 0.31 . The same spatial range $(-0.2 \div 0.2 \mathrm{~cm})$ was found for the Gauss filter, WienerKolomogorov filter, and ANS filter, but for the CNES/GRGS filter, the vertical spatial distribution was within the range $(-1 \div 1) \mathrm{cm}$.

\subsection{Prediction of Earth orientation parameters and the related geophysical parameters}

Wavelet based techniques allow to perform a time-frequency comparison of the geodetic (computed from pole coordinates data) and fluid excitation functions (Kosek et al., 2011a). These two functions became the most similar when the fluid excitation function was composed of the atmospheric, ocean and land hydrology excitation functions. Higher order semblance function revealed that addition of hydrology angular momentum to the sum of atmospheric and oceanic ones improves the phase agreement between the geodetic and fluid excitation functions in the annual frequency band. The wavelet based semblance filtering enabled the determination of the common signals in both excitation functions. Increase in 
the threshold value in the semblance filtering of the geodetic and fluid excitation functions increased the correlation coefficients values between the filtered common oscillations.

In October 2010 the US Naval Observatory in Washington together with the Space Research Centre in Warsaw initiated the Earth Orientation Parameters Combination of Prediction Pilot Project (EOPCPPP) to compute EOP predictions on an operational basis (Kosek et al., 2011b). The pole coordinate data predictions from different prediction contributors and ensemble predictions computed by the U.S. Naval Observatory were studied to determine the statistical properties of polar motion forecasts by analysing second, third (skewness) and fourth (kurtosis) statistical moments about the mean value. It was found that prediction errors of pole coordinates data do not satisfy normal distribution. The skewness values for different participants showed that the probability distribution becomes more asymmetric when the prediction length increases. The kurtosis values usually decreases with the prediction length, which means that the probability distribution becomes more flat and has larger tails than a normal distribution.

Kosek (2012) found that short-term prediction errors of pole coordinates data were caused by wideband short period oscillations in joint atmospheric-ocean excitation functions. Some large prediction errors of pole coordinates data in 1981-1982 were caused by wideband oscillations in ocean excitation functions while in 2006-2007 they were caused by wideband oscillations in joint atmospheric-oceanic excitation functions (Fig. 6). It had been shown that the combination of the prediction methods treating

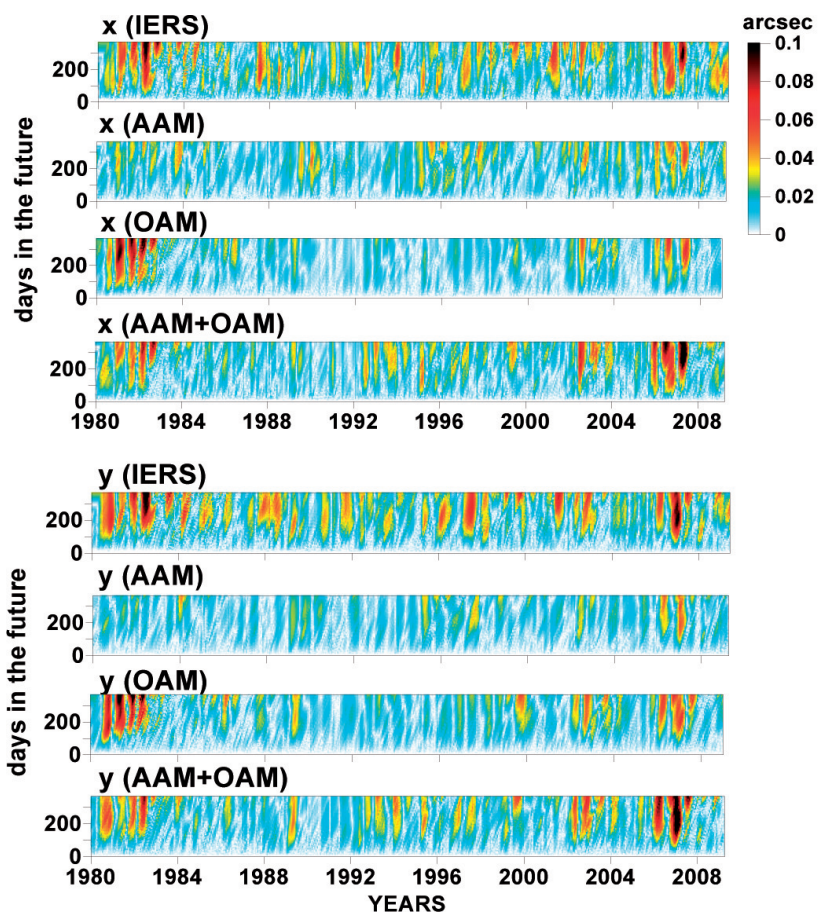

Fig. 6. The LS + AR prediction errors of IERS pole coordinates data and of pole coordinates model data computed from AAM, OAM and AAM+OAM excitation functions (Kosek, 2012) 
separately deterministic and stochastic part of the EOP can provide the best accuracy of the prediction. The recommended prediction method for pole coordinates data is the least-squares (LS) and autoregressive (AR) combination and the Kalman filter is recommended for the prediction of UT1-UTC data. Short term prediction errors of the EOP data are not caused by variable amplitudes and phases of the most energetic oscillations in these data because they are much smaller when the data are smoothed by removing the frequency components computed using the discrete wavelet transform band pass filter.

To forecast the IERS UT1-UTC, which is necessary for real-time transformation between the terrestrial and celestial reference frames, the combination of LS extrapolation of a polynomial-harmonic model with the multivariate autoregressive (MAR) prediction technique had been proposed (Niedzielski and Kosek, 2012b). The method uses the bivariate time series comprising length of day data corrected for tidal effects and the axial component of AAM data. The superior performance of the MAR prediction in comparison to the AR one was observed, in particular during El Niño and La Niña events. The mean prediction error of the UT1-UTC data for the LS+MAR combination is usually smaller than for the LS+AR one, and the proposed method is recommended to improve longer term forecasts of these data.

\subsection{Research on associated geodynamic phenomena}

\subsubsection{Geocenter motion}

The spectra-temporal wavelet semblance with the application of the modified Morlet wavelet function enables computation of correlation coefficients between the centre of mass time series determined by Doppler Orbitography and Radiopositioning Integrated by Satellite (DORIS), Global Navigation Satellite Systems (GNSS) and Satellite Laser Ranging (SLR) techniques as a function of time and frequency (Kosek et al., 2014). The highest positive semblance values occur in the $X Y$ equatorial plane for the retrograde annual oscillation in the GNSS and SLR data as well as prograde annual oscillation between DORIS and other two techniques. The spectra-temporal semblance functions in $Y Z$ plane between the centre of mass time series of SLR and other two techniques show annual prograde oscillation. The wavelet-based semblance filtering with application of the Shannon wavelet functions enabled computation of common signals in the time series of geocenter motion. The most energetic part of this signal is the retrograde annual oscillation in the equatorial plane with amplitude of $2-3 \mathrm{~mm}$ and this oscillation is out of phase between DORIS and two other techniques. These common signals constructed using lower frequency components enable determination of the smoothed geocenter time series model (Fig. 7). 


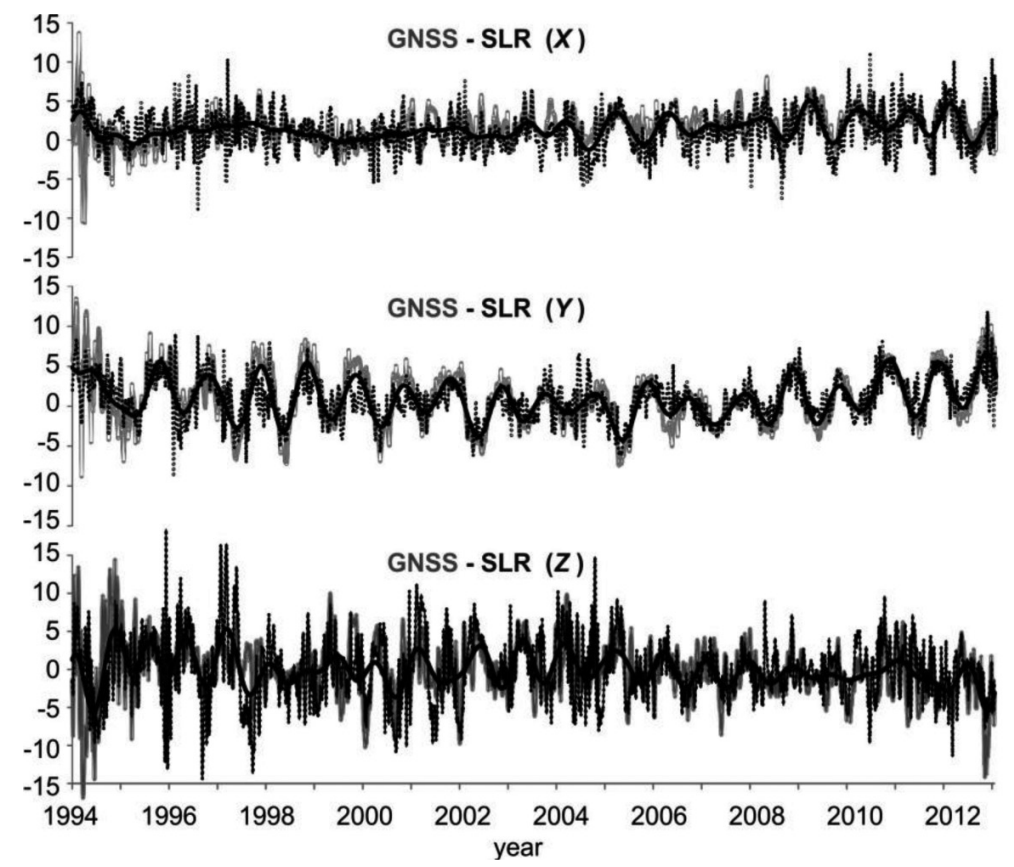

Fig. 7. The model centre of mass time series (bold) computed as the average of the GNSS (gray) and SLR (dotted) common oscillations composed of only 6 lower frequency components together with the filtered oscillations (Kosek et al., 2014)

\subsubsection{Sea level change}

Niedzielski (2011b) showed the results of analysis focusing on optimal orders of autoregressive models determined for sea level anomaly (SLA) residuals. Memory of stochastic processes - those that govern irregular sea level residuals at various locations - is rather weekly organized in space. In the vicinity of Indonesia, and in certain areas of the central and eastern equatorial Pacific Ocean, there exists a poorly organized concentration of grid cells in which sea level residuals are described by high-order models. Associated with this is an investigation into the El Niño-Southern Oscillation (ENSO) impact on sea level change in the equatorial Pacific. Niedzielski and Kosek (2011a) compiled their results and provided a comprehensive characterization of how ENSO influences sea level modelling experiments. Now, sea level change studies are migrating towards processing time series offered by the Archiving, Validation and Interpretation of Satellite Oceanographic data (AVISO) repository. Near-real time and delayed time data are to be analyzed, modelled and predicted. The near-real time system and service for sea level prediction, known also as Prognocean was designed, implemented and based at the University of Wroclaw. Initially, gridded daily SLA data, known also as MSLA, obtained courtesy of AVISO repository are predicted for 1, 7 and 14 days in the future. Along with predictions, Root Mean Squared Error (RMSE) 
of predictions is computed in near-real time so that the users are able to evaluate the performance of the system and service. The following prediction methods were implemented: 1) extrapolation of a polynomial-harmonic model built for deterministic components and the combination of this method with 2) autoregressive prediction of residuals, 3) threshold autoregressive model and 4) multivariate autoregressive model (Niedzielski and Mizinski, 2013).

The sea level anomalies based on satellite altimetry data available from AVISO website were analysed (Kosek et al., 2013). The time-frequency analysis based on the Fourier Transform filter of these data enables to detect ocean regions where the signal in sea level change is not linear. It has been found that the annual oscillation in these data is not linear, has a broadband character, and it is mostly responsible for the increase of short-term prediction errors of sea level anomaly data. It creates oscillations with frequencies being an integer multiplicity of the annual frequency. Thus, amplitude maxima of all these shorter period oscillations are located almost in geographic regions of the annual oscillation amplitude maxima. The increase of the prediction errors of sea level anomaly data is mostly caused by variable amplitudes and phases of the broadband annual oscillation. Swierczynska et al. (2014) demonstrated that the asymmetry between El Niño and La Niña events recorded in sea level variation occurs only during extreme episodes of ENSO. They also explained that the asymmetry is controlled by certain regular cycles with time-variable amplitudes.

The stochastic low-order autoregressive moving average (ARMA) and generalized autoregressive conditional heteroscedastic $(\mathrm{GARCH})$ models were used to model irregular sea level fluctuations in the least-squares residuals of the sea level anomaly data (Niedzielski and Kosek, 2011b). The authors found that AR and ARMA models are adequate, with a successful fit to these residuals in some patchy bits of the equatorial Pacific. In contrast, GARCH models have been shown to be rather inaccurate, specifically in the vicinity of the tropical Pacific, in the North Pacific and in the equatorial Indian Ocean. The pattern of the Tropical Instability Waves (TIWs) called also Legeckis waves has been observed in the statistics of AR and ARMA model residuals indicating that the dynamics of these waves cannot be detected by the linear stochastic processes. It was shown that it is rather difficult to unequivocally recommend particular models for the forecasting capable to describe the nonlinear sea level anomalies present in the equatorial Pacific and the tropical Indian Ocean.

Niedzielski and Kosek (2012a) reviewed statistical properties of sea level fluctuations observed by TOPEX/Poseidon and Jason-1 altimetry missions, both on global and regional scales, as well as different temporal domains including long-, medium-, and short-term components of sea level fluctuations. It was shown that ENSO-driven signal in sea level change extends from east towards central Pacific, as indicated by unexpectedly coherent spatial patters of a few statistical measures (Fig. 8). The authors found that there is a zone in central Pacific where skewness of sea level variability is approximately equal to 0 and kurtosis is equal to 3 . In addition, the standard deviation of sea level variation is lower in such areas. The zone in question may be interpreted as the boundary of ENSO-driven fluctuations of sea level. 

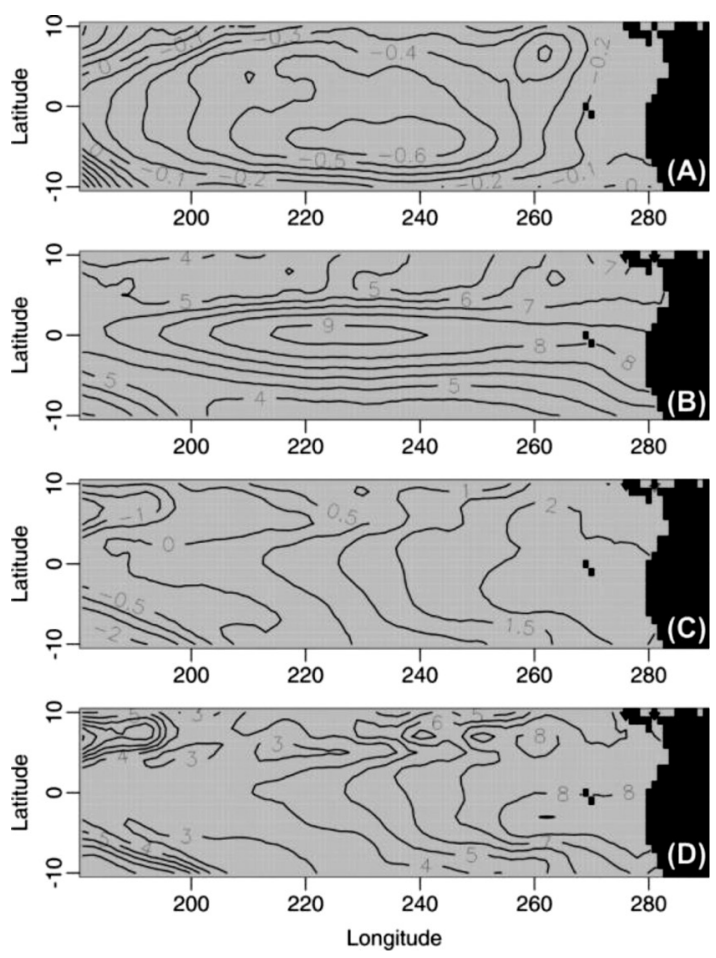

Fig. 8. Maps showing sea level change statistics: rate in $\mathrm{cm}$ per year (A), standard deviation in $\mathrm{cm}(\mathrm{B})$, skewness (C), and kurtosis (D) (Niedzielski and Kosek, 2012a)

The Cox-Stuart statistical test was used to estimate a minimum time span of the global mean sea level time series from TOPEX/Poseidon, Jason-1 and Jason-2 satellite altimetry which is sufficient to detect a statistically significant trend as well as to detect a significant acceleration in these data (Niedzielski and Kosek, 2011a). Considering the set of significance levels equal to $0.002,0.004, \ldots, 0.1$, the test was applied to compute the probability of trend detection in the global mean sea level time series in 1993-2010. It was found that whether these data were corrected for the Global Isostatic Adjustment (GIA) or not, the statistically significant trend can be detected with the probability close to 1 when these time series length is approximately equal to 2.99 and 3.09 years, respectively. Assuming available altimetry global mean sea level data it was impossible to detect any acceleration in sea level rise with the probability close to 1 .

Niedzielski (2014) presented a review of ENSO and selected environmental consequences at a range of spatial scales. The fundamentals of ENSO were summarized in a descriptive way, and the key facts from the history of ENSO research as well as with recent developments in understanding the oscillation were given. Subsequently, a potential initial driving force that begins the warm ENSO episode was discussed, and the inference was limited to the Quasi-Biennial Oscillation which may be controlled by solar forcing. Later, the insight into the ENSO history was provided, with a scrutiny about the most recent phenomena and the ENSO variability over the geological time. Three 
environmental consequences of ENSO: irregular fluctuations of the EOPs, climatic and hydrologic teleconnections that allow migration of the ENSO signal to remote regions of the Earth (the teleconnections are explained using the specific European example), and sea level change in the equatorial Pacific and Indian Oceans were discussed. Those examples explain that ENSO is a phenomenon that impacts the dynamics of the entire Earth and controls some geophysical and environmental parameters of the atmosphere and hydrosphere on regional and local scales.

\subsubsection{Hydrological processes}

The aforementioned didactic paper by Niedzielski (2011b) also included topics related to hydrological processes and their characterization. A complete series of maps that complement previous work by Sen and Niedzielski from 2010 was published and discussed to illustrate a combination of time series and the Geographic Information System (GIS) methods. In particular, a moment-based characterization of discharge data at a given outlet is combined with a GIS-based description of basin topography.

Recent investigations confirm meaningful but weak teleconnections between ENSO and hydrology in some European regions. In particular, it holds for Polish riverflows in winter and early spring as inferred from integrating numerous geodetic, geophysical and hydrologic time series. Niedzielski (2011a) examined whether such remote teleconnections may affect hydrologic forecasting. On the basis of cross-correlation and wavelet analyses it was found that there is a weak but significant link between ENSO and surface hydrology in SW Poland. It was inferred that ENSO episodes may be among a few factors affecting winter and early spring discharges of rivers in SW Poland and may have a (probably limited) impact on snow-melt flood generation.

The new HydroProg system is now experimentally implemented at the University of Wroclaw for the upper Nysa Klodzka and its selected water gauge in Klodzko Valley. The aim of this system is real time prediction of water level in Odra River as well as warning of the potential hazard, its type and location.

\section{Monitoring of geodynamic phenomena}

\subsection{Permanent GNSS observations}

Determination of strain. Analysis of time series based on data from permanent GNSS stations allows to study the precision of station velocity determination as well as crustal deformation due to hydrological loading. Bogusz et al. (2013b) presented the results of testing of various methods of permanent stations' velocity residua interpolation on a regular grid, which constitutes a continuous model of the velocity field in the territory of Poland. Absolute velocities expressed in the ITRF2005 and the intraplate velocities related to the Northwest University Velocity (NUVEL) and Actual Plate Kinematic 
Model (APKIM) tectonic plate motions models at over 300 permanent reference stations of the EUREF Permanent Network (EPN) and Polish Active Geodetic Network (ASG-EUPOS) covering the area of Europe were investigated. Based on the velocities of permanent EPN stations, the map of the continuous velocity field was developed by interpolating velocities using the Kriging method with the nugget effect (Fig. 9).

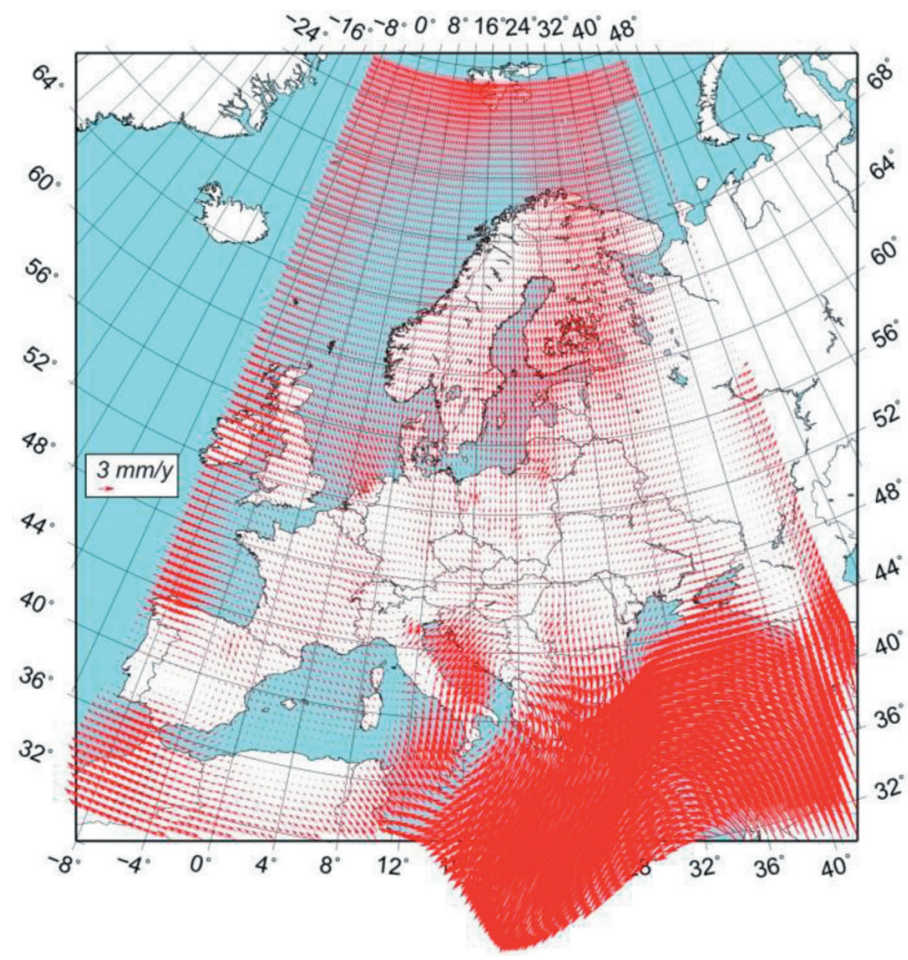

Fig. 9. The continuous intraplate velocity field for Europe with the use of APKIM2005 (IGN) model

Robustness of geodetically-defined kinematic model describing recent geodynamics was tested using numerical finite element modelling of stress and strain distribution in Central Europe (Bogusz et al., 2011). Simplified mechanical model of the lithosphere was developed using geological and geophysical data including tectonically defined discontinuities. The results of model predictions (Fig. 10) were evaluated by comparison with measured present-day stress and strain.

Residual time series of solutions obtained by the routine GNNS data processing (ETRF2000) were analyzed to test the models used and to find error sources that could possibly affect solutions by decreasing their reliability (in the terms of precision). There are many doubts regarding proper antennas' placement - as they are mostly installed on the roofs of the buildings. The use of data from such sites for the purpose of geodynamic study, like intra-plate velocity or strain estimations was questioned. Bogusz et al. (2012b) presented the usefulness of ASG-EUPOS time series for the determination of 


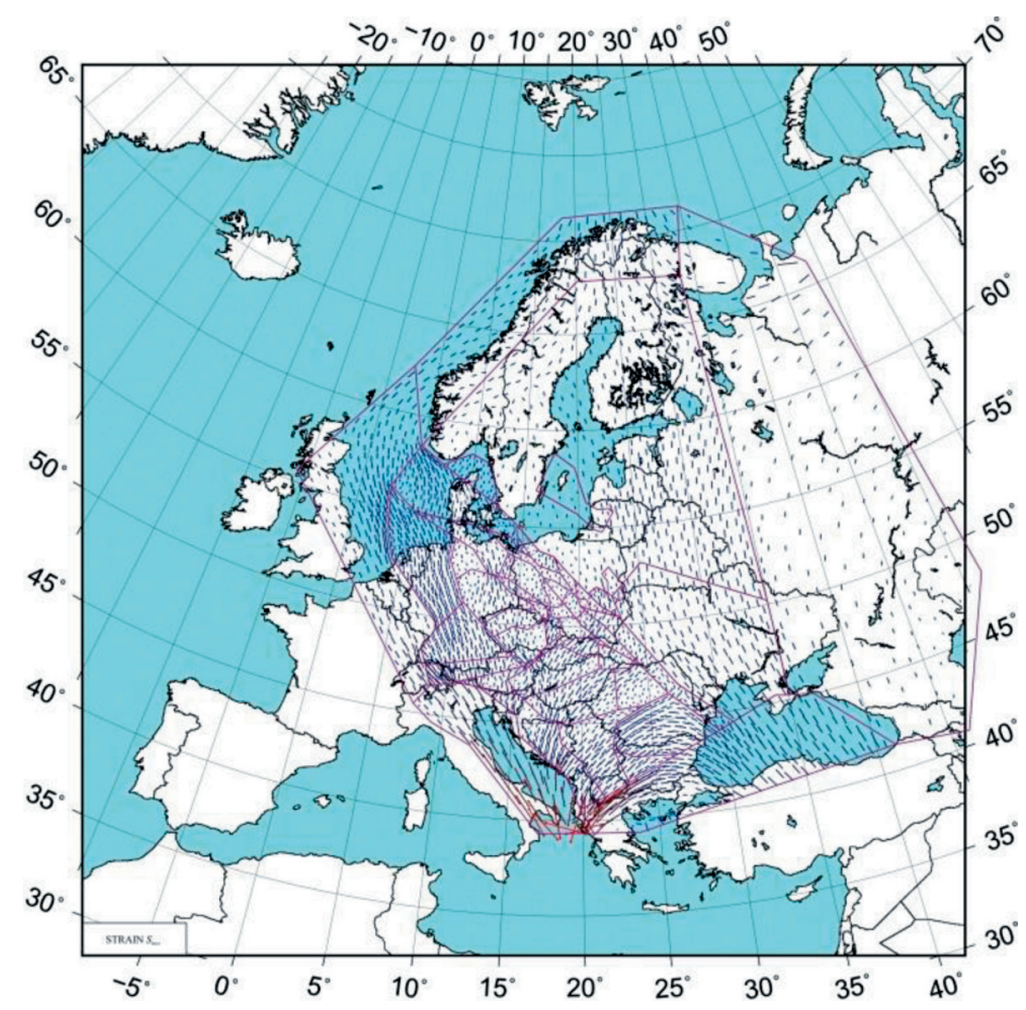

Fig. 10. Strain directions $\left(\mathrm{S}_{\mathrm{MAX}}\right)$ obtained using Finite Element Method modelling

the regional velocity field. Calculations were performed using robust estimation instead of the least squares method due to its disadvantages, e.g. the small robustness for the large errors (stand-off values) that significantly affect estimated parameters. The velocity field was developed using the observations from the newly established (2008) ASGEUPOS system. The intraplate velocities (IPV) were determined using geological model NUVEL-1A NNR and geological-geodetic APKIM2005 model (Bogusz and Figurski, 2012). They were compared with those obtained using geodetic techniques (ITRF global velocities and the European Terrestrial Reference Frame - ETRF ones) and large discrepancies between available models were highlighted. Due to the observed ambiguities the authors recommended the use of the absolute (ITRF) velocities and proposed the method of their verification (Bogusz et al., 2013a). Selection of the criteria qualifying insufficiently stable points to be eliminated from further computations is of a great importance for the final solution of the deformation field. In the area of Poland, which is a tectonically stable region, the strain should not exceed 3 to 4 nanostrains/ year. The disturbances resulting from insufficient stability of the ASG-EUPOS stations affect significantly the computations of the deformation field. The GRID_STRAIN software that runs under the MATLAB ${ }^{\circledR}$ environment helped to achieve the continuous strain field model after the final data verification (Fig. 11). 


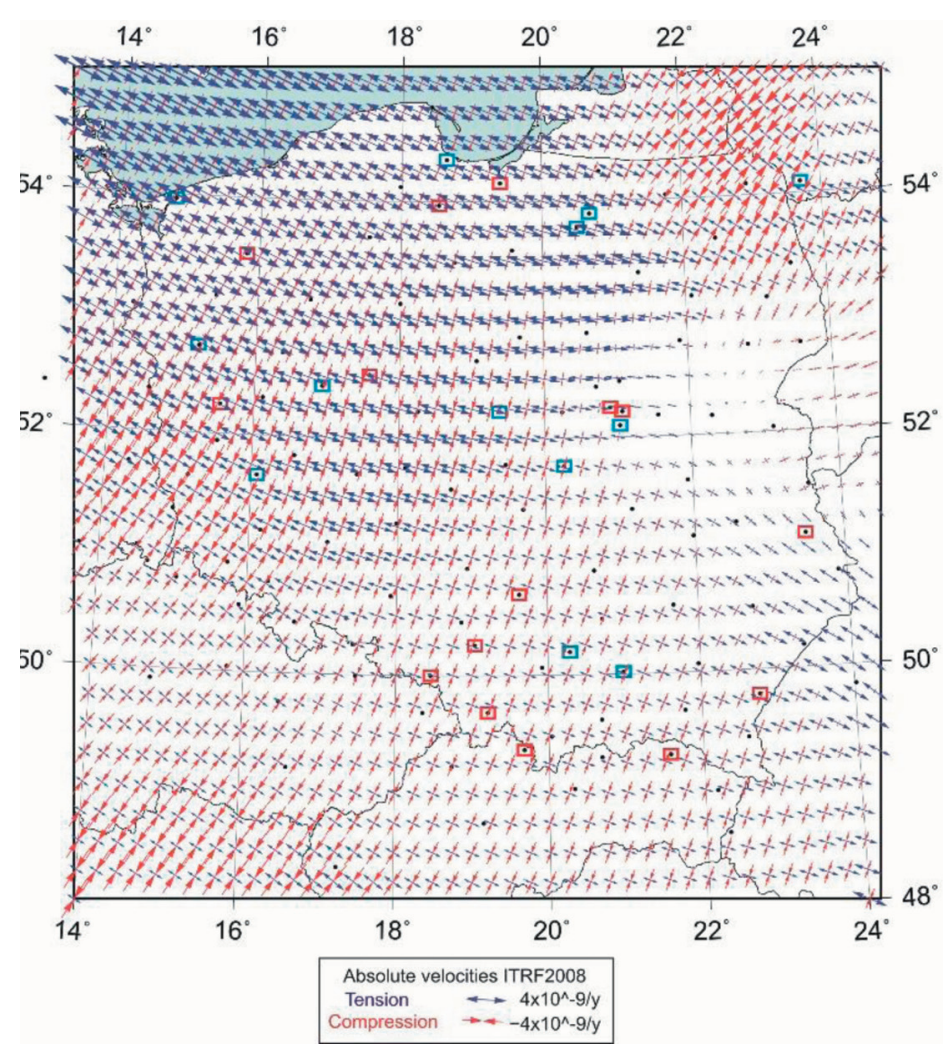

Fig. 11. Continuous strain field after the final data verification (the excluded stations are also marked to show what influence they had on the appearance of the strain field) (Bogusz et al., 2013a)

Periodic oscillations observed on several sites are probably related to the real effects from atmosphere or continental hydrosphere. Rajner (2012) analysed the temporal and spatial range of the Earth' tides, ocean tidal loading, atmospheric radiation tides loading, polar motion and its oceanic indirect effect and the non-tidal ocean loading with pointing on their magnitudes and possible effects on high precision positioning with space geodetic techniques. The author studied these effects for Jozefoslaw station of WUT.

Rajner and Liwosz (2011) described the large-scale crustal deformation due to hydrological surface loads computed basing on WaterGAP Hydrological Model with Green's functions. They focused on its influence on seasonal variation of GPS-estimated heights using the Precise Point Positioning (PPP) method. They analysed time series for 4 stations from the area of Poland. A good agreement in both amplitude and phase with $10 \mathrm{~mm}$ of peak to peak was found for hydrological surface loads and GPS heights. The authors developed a simple model for Poland that may help to reduce the seasonal signal in GPS solutions.

Satellite data from the ASG-EUPOS stations enable also the determination of the model of vertical crustal movements for the territory of Poland. The high credibility of levelling data is evaluated by a number of control procedures and statistical evaluation 
before and after adjustment, as well as during the measurement activities. Kowalczyk et al. (2014a) used daily height differences from 35 ASG-EUPOS stations determined in the EPN Local Analysis Centre at the Military University of Technology (MUT LAC) using Bernese v.5.0 software. The vectors between permanent stations for calculating the height differences were chosen with the use of Delaunay triangulation. The standard deviations of height differences vary from $3.0 \mathrm{~mm}$ to over $6.2 \mathrm{~mm}$. The average misclosure equals $\sim 0.3 \mathrm{~mm} /$ year, while the maximum misclosure is equal to $\sim 1.0 \mathrm{~mm} /$ year.

The correlation between two models of vertical crustal movements was determined using two methods: absolute and relative (Kowalczyk et al., 2014b). On the basis of the obtained results the qualitative and quantitative possibility of the use of data from GNSS permanent stations for developing a kinematic model of vertical crustal movements was discussed (Fig. 12).

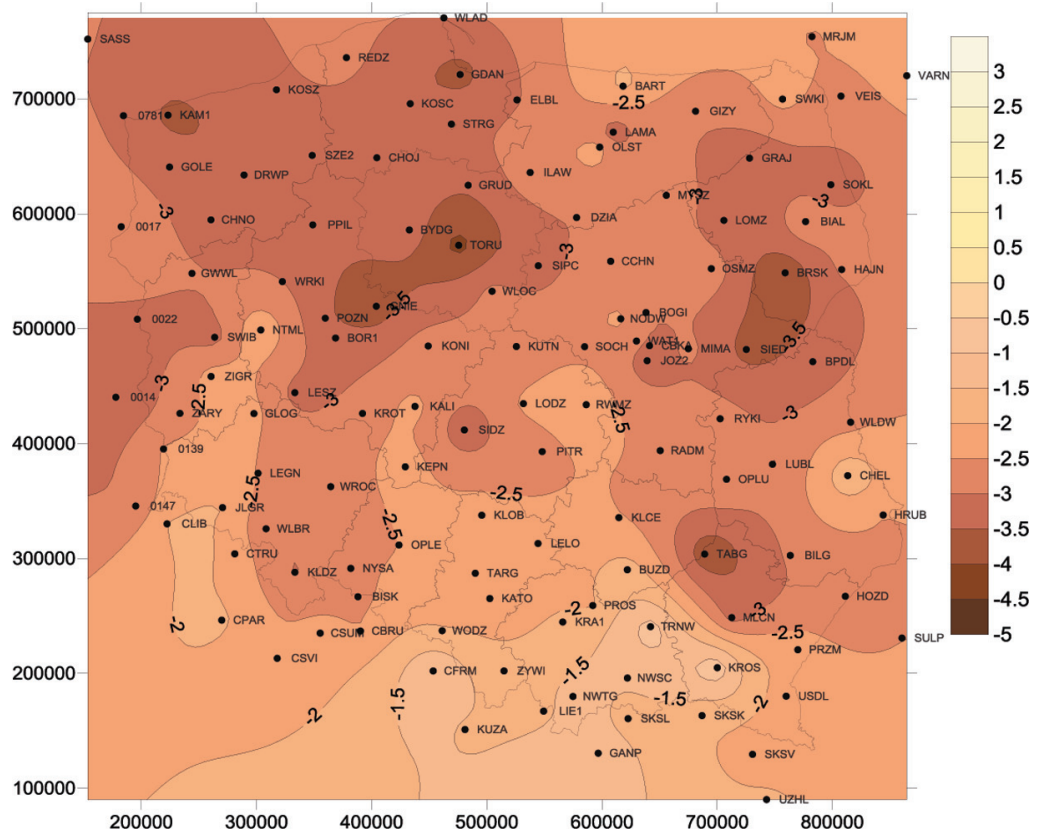

Fig. 12. Developed model of vertical crustal movements [mm/y] (Kowalczyk et al., 2014b)

The GPS time series autocorrelations can be identified both in the deterministic and stochastic part of the data. Their existence in the deterministic part of GPS time series is identified as a trend (interpreted as station's velocity) and seasonal components (annual and semi-annual). The autocorrelation in the stochastic part of GPS time series was proven in the form of its power-law long-range dependencies with the use of numerous of methods. The use of locally weighted scatterplot smoothing (LOESS) was tested in the autocorrelation analyses (Bogusz et al., 2014a). It was shown that the trendrelated behaviour is best modelled by both smoothing parameter and polynomial of degree 1 . The $2^{\text {nd }}$ degree polynomial with smoothing parameter close to 0.1 fits seasonal 
components quite well. For all of the LOESS modelled curves, the autocorrelation function $(\mathrm{ACF})$ was calculated for different types of modelled phenomena. The goodness of fit of the linear regression line into topocentric components of velocity determination was investigated for the selected ASG-EUPOS and EPN stations (Bogusz et al., 2014b). The coefficient of determination $R^{2}$ close to 1 proves the well fitted LS line into the time series, while its lower values reflect the effect of unremoved (or improperly removed) outliers, offsets and seasonal components. This clearly demonstrates how the determination of the velocity of permanent GNSS stations can suffer from the incorrect data pre-analysis.

\subsection{Permanent SLR observations}

Due to serious failures of the laser module and telescope system the Borowiec SLR station (SOD 78113802) is offline since 25 March 2010. At the beginning of 2014 new telescope optic was replaced including primary and secondary mirror of the telescope (Cassegrain system) and special dielectric mirrors transferring laser pulse from laser unit to the telescope. Additionally, two laser modules were installed, the standard unit used for laser observations of all ILRS satellites and high-energy module dedicated to laser observations of space debris. First attempts towards observations of all ILRS objects were carried out in October 2014.

Alothman and Schillak (2014) presented a new SLR-derived velocity for the Arabian plate motion, based on data from 1996 to 2009 from SLR station at Riyadh. They calculated satellite arcs in ITRF2008 using SLR observations from about 20 ILRS stations with the GEODYN-II software. The velocity of Riyadh station was determined by fitting the linear regression line into time series of position changes. The $3 \mathrm{D}$ velocity determined equals $42.9 \pm 0.2 \mathrm{~mm} /$ year with North, East and Up components of 29.1 \pm 0.2 , $31.6 \pm 0.2$, and $1.9 \pm 0.3 \mathrm{~mm} /$ year, respectively. It is similar to the one from NNR NUVEL1A geological model.

Lejba and Schillak (2011) determined the positions and velocities of four SLR stations: Yarragadee (7090), Greenbelt (7105), Graz (7839) and Herstmonceux (7840) in ITRF2005 from 5-year observations of low orbiting (LEO) satellites (Fig. 13) using GEODYN-II software and compared the results with the respective ones derived from processing LAGEOS-1/LAGEOS-2 observations. The authors showed that the stability of station coordinates obtained from LEO satellites is in general worse $(17.8 \mathrm{~mm})$ than those from LAGEOS $(7.6 \mathrm{~mm})$. The velocities of analyzed stations were determined with the accuracy of $1 \mathrm{~mm} /$ year, and $0.5 \mathrm{~mm} /$ year when using observations of LEO satellites, and LAGEOS satellites, respectively.

Szafranek and Schillak (2012) presented the models, parameters and assumptions made for homogenous reprocessing of SLR and GNSS data from 1996-2011 in the NAPEOS software. The paper was related to the recommendation of the Global Geodetic Observing System (GGOS), which stated that the same models and parameters from IERS Conventions 2010 should be used in both processing strategies. 
Strong earthquakes and tsunamis affected many stations being the core of the ITRF by position discontinuities, which caused their temporal uselessness as the reference. As a consequence, the decrease of the quality of the network geometry also occurs. The Earth crust stresses and post-seismic relaxation damages occurring near the Earth surface can be mentioned as the main reasons of coordinates change. After the earthquake the shape of time series of station coordinates can be described by curve line with dumping amplitudes (so-called "post-seismic decay"). The impact of earthquakes on the stability of time series on the selected GNSS and SLR co-located sites was investigated (Szafranek et al., 2014). GNSS and SLR data from selected co-located sites were processed to investigate the optimal method of post-seismic decays determination as well as to determine the time necessary for each station to attain the stability again.
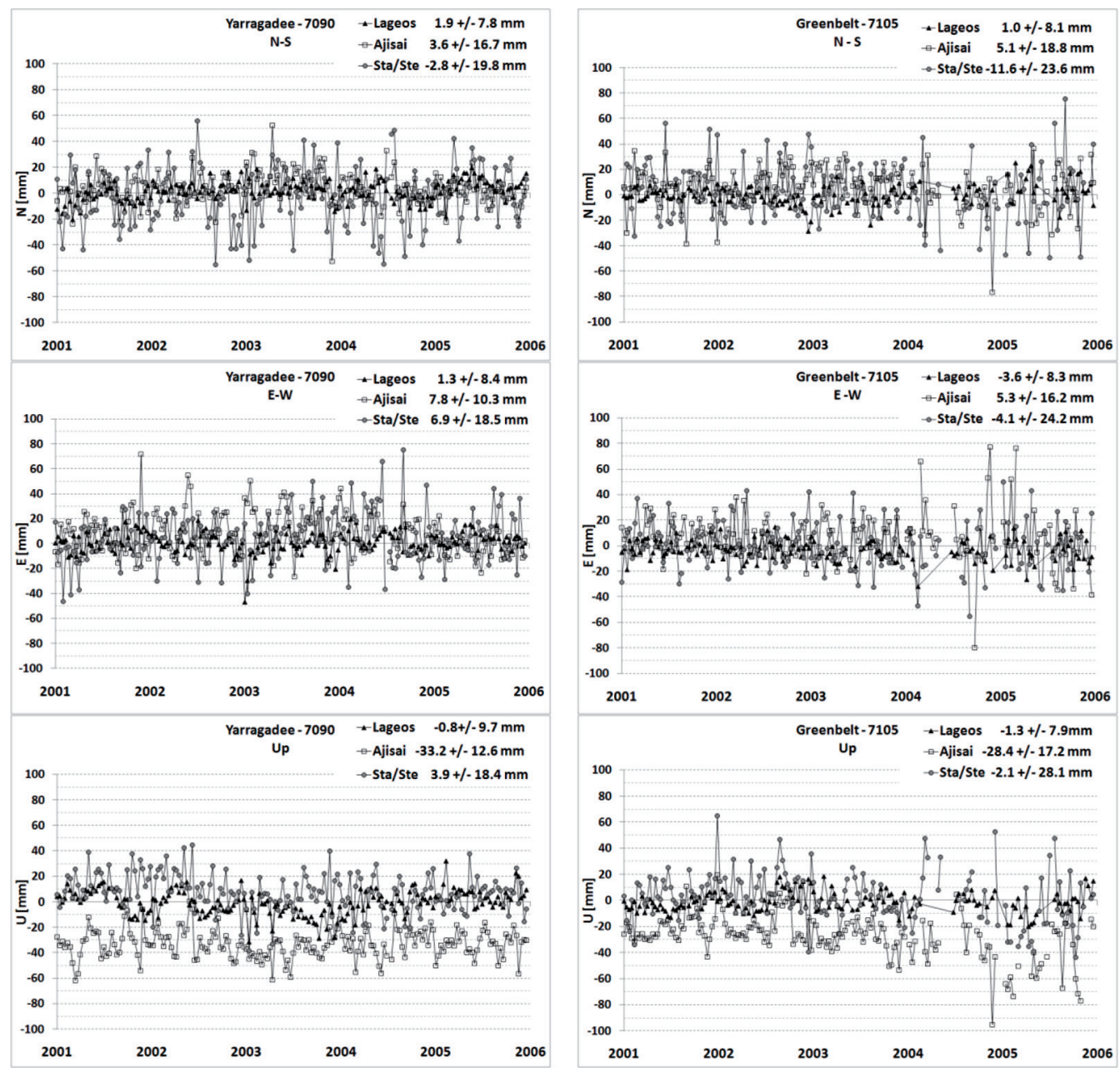

Fig. 13. Yarragadee (West Australia) and Greenbelt (MD, USA) positions (N, E, U) from Starlette/Stella, Ajisai and LAGEOS-1/LAGEOS-2 satellites in reference to ITRF2005 for epoch 2000.0

(Lejba and Schillak, 2011) 


\subsection{Local geodynamic networks}

The geodynamic network of the Sudety Mts. (GEOSUD) was established in Poland in 1996. Simultaneously, the geodynamic network EAST SUDETEN was built on the Czech side of the border in 1997 and in 2001 it was extended for sites towards west (the WEST SUDETEN network). Since 1997 annual GPS campaigns have been performed on both networks.

Kaplon et al. (2014) focused on the results of uniform reprocessing of all measurements from the geodynamic network of the Sudety Mts. from 1997-2012. The earlier GPS observations were processed few times using the Bernese software applying different models for EOP, satellite ephemeris, pole motions, ocean loadings and antenna calibrations. The authors reprocessed the whole data set homogenously and obtained ITRF2008 coordinates and velocities have been compared with respective EPN and ASG-EUPOS solutions. The determined velocities (Fig. 14) reflected the complexity of geological structures of the examined area, where individual Sudetic and Moravo-Silesian blocks of the Bohemian Massif are affected by active dynamics of the West Carpathians and Alpine orogene structures.

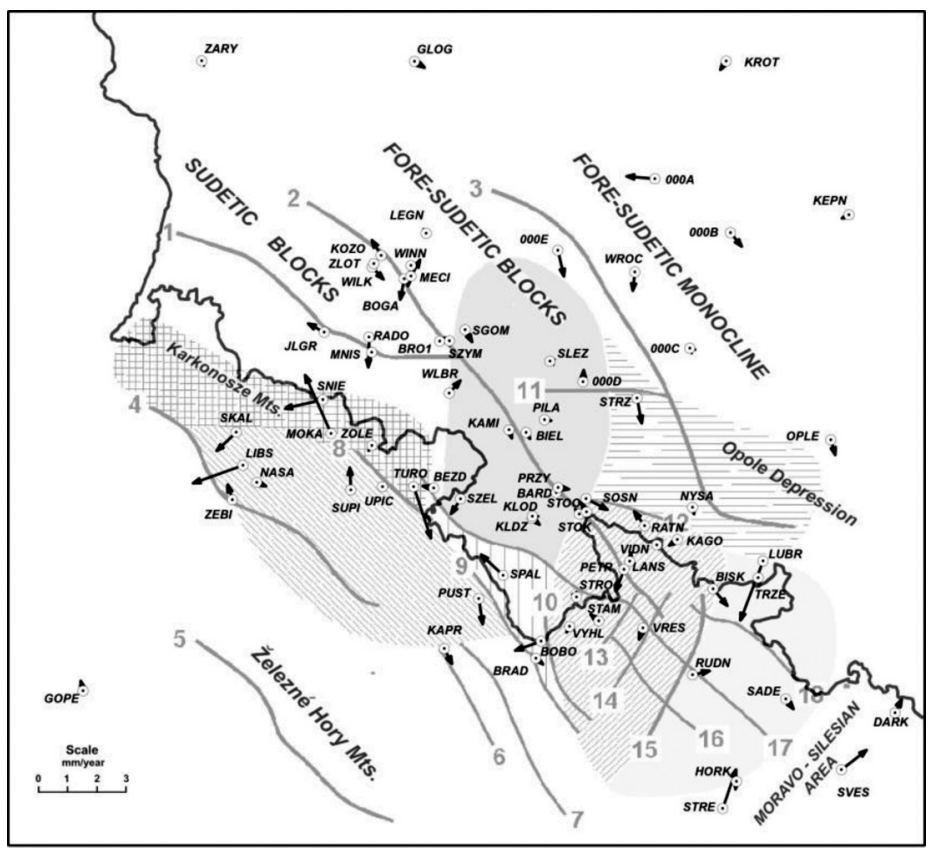

Fig. 14. Vectors, 5 of horizontal intraplate velocities (ITRF2008 reduced with ITRF2008 plate-motion model) (Kaplon et al., 2014)

Grzempowski et al. (2012) investigated the changes in the elevation of benchmarks of precise levelling lines between 1956-1999 and compared them with GPS solutions from 2008-2010 in the framework of geodynamic studies on Wroclaw Plain, situated 
in the SE part of Central European Subsidence Zone (CESZ). On the basis of levelling data, the authors found out the subsidence of Wroclaw Basin that increases the basin margins. Consideration of GPS data lead to the detection of the compressive strain in the axial part of the CESZ southwest of Wroclaw along W-E direction and in Opole depression along NNW-SSE direction. The extensional strain was shown to occur at the southern CESZ margin, along the W-E direction in the uplifted part of the ForeSudetic Block and at the northern margin of this zone, along W-E and NW-SE directions (Fig. 15).

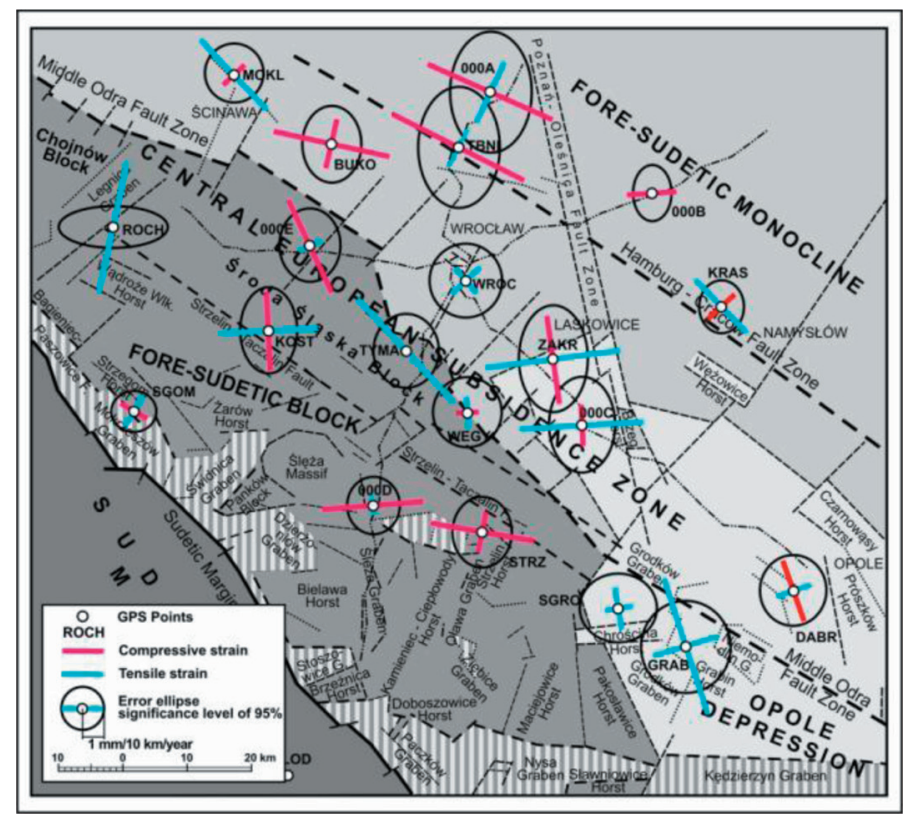

Fig. 15. Horizontal strain in the study area calculated on the basis of velocities of GPS points obtained from measurements in 2008-2010 (Grzempowski et al., 2012)

Cacon et al. (2012) presented the results of repeatable precise levelling in three geodetic micro-networks from Szczeliniec Wielki in the Bohemian Massif. The authors confronted the results of levelling and displacements from 3D monthly records with recent investigations of tectonic micro-deformations. Analysis of precise levelling data and data acquired with a total station showed changes in heights of selected network points, what confirmed the gravitational deformations in that area. The recent geodynamic effects were recognized as ones of an aseismic origin.

Bogusz et al. (2012a) determined the horizontal velocity field derived from 3-years' time series of topocentric components of the EPN and ASG-EUPOS stations. The determination of the velocity field was performed using robust estimation ( $M$-estimators). The presented effects, which could decrease the velocity estimation reliability, have been grouped into four categories. Finally the regional absolute and intraplate velocity fields were presented (Fig. 16). 

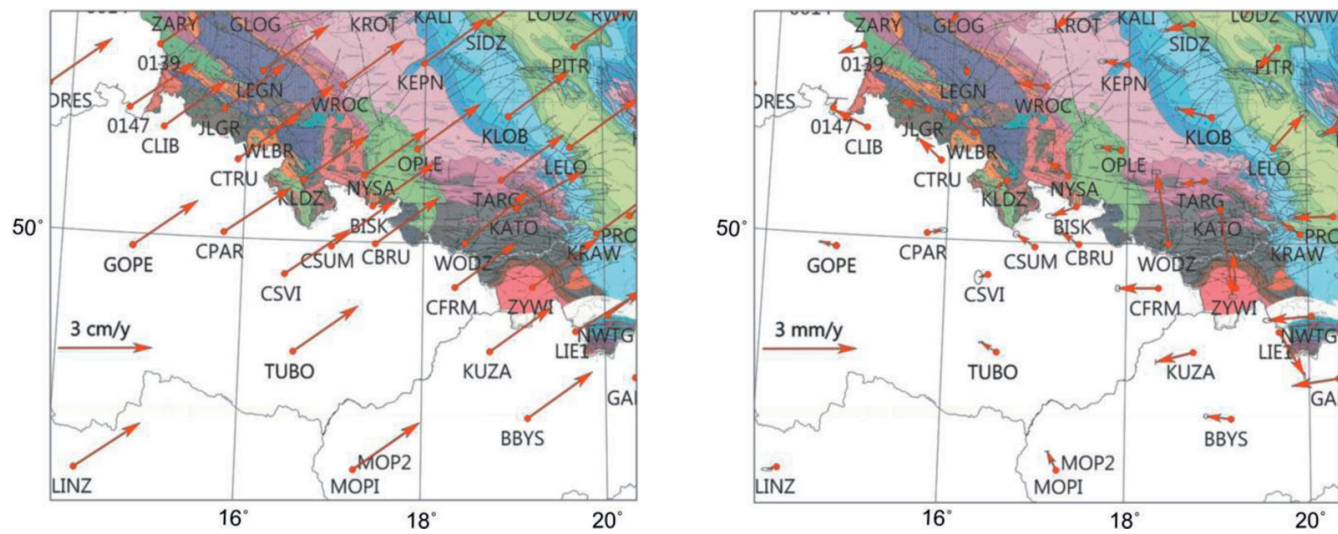

Fig. 16. Absolute (in ITRF2005, left) and intraplate (in ETRF2000(R05), right) velocities with error ellipses (Bogusz et al., 2012a)

Rajner et al. (2012) have studied the effect of gravity variations associated with the changes of soil water on global scale in Lower Silesia (SW Poland). They used data acquired with the FG5-230 gravimeter of $2 \mu$ Gal peak to peak amplitude and showed that neglecting the changes of soil may result in detecting secular gravity changes which is an artefact.

Ksiaz Observatory. The Ksiaz Massif is located in the central part of a structural geological unit known as the Swiebodzice Depression/Basin, which belongs to the regional mosaic of evolving Sudetic Palaeozoic sedimentary basins. A water-tube tiltmeter (WT) system consisting of two perpendicular tubes was installed in the underground galleries of the Geodynamic Laboratory of the SRC in the Ksiaz Castle, Central Sudetes, in 2003. The partially filled water tubes of several tens of metres long are equipped with high-precision interferometric recording gauges at their ends. The recording gauges continuously measure water level changes in the tubes with single-nanometre accuracy which corresponds to 0.005 mas of plumb line variations. Kaczorowski and Wojewoda (2011) discussed the phenomenon of great non-tidal signals recorded by the two water-tube tiltmeters of the Geodynamic Laboratory in Ksiaz. They found strong symmetrical and asymmetrical signals in water level variation, which may origin from active bedrock deformation due to contemporary tectonic movements of the Ksiaz Massif. The authors concluded that if the fault blocks are a subject of 3D rotations, the WT tiltmeter would detect only the vertical component of block movement. Kaczorowski (2013) found the harmonic oscillations of water level changes in two water-tube tiltmeters in Geodynamic Laboratory in Ksiaz that were unrecognized before. Their amplitudes are of several hundred nanometres and frequencies of a dozen or so harmonic modes from 10 to 100 minute periods $\left(10^{-3} \mathrm{~Hz}\right)$. The author concluded, that the signals are propagated in the atmosphere and tried to find out the origin of these infrasounds. He excluded a range of phenomena from the nearest surrounding of laboratory and stated that the observed micro-vibrations of air pressure can be generated thousand kilometres away. Kasza et al. (2014) described tectonic activity in the Ksiaz area derived from water-tube tiltmetres data and surveying data 
from the network in underground corridors of Geodynamic Laboratory. The presence of several zones of tectonic faults of rock mass was shown. The results confirmed the geodynamic nature of signals recorded by WT caused by vertical movements and the slopes of rock blocks during tectonic events. Numerous comparisons confirmed that the damages observed in the structure of Ksiaz castle can be caused by recent tectonic activity. In 2010 became operational a GPS station KSIA devoted to investigate the episodic displacements of rocks in the Ksiaz Massif to support the interpretations made with water-tubes in the Geodynamic Laboratory, in particular to reduce the disturbance effects of geophysical origin from water-tubes analysis (Zdunek, 2012). The 3-years long time series from GPS KSIA and KSI1 stations (Fig. 17) was analysed (Zdunek et al., 2014). The velocity vector determined for that station was compared with velocity vectors of others selected reference stations located in different azimuths, tectonic units and distances from KSIA. Different displacements of the Swiebodzice Depression and Ksiaz unit in relation to selected GPS stations were observed. Significant deformation of the Pelcznica river meander, geological indicators such as trends and dips of faults as well as kinematic models of deformations of Ksiaz massif indicate possible interpretation of the reasons of differences between KSIA GPS station displacements determined.

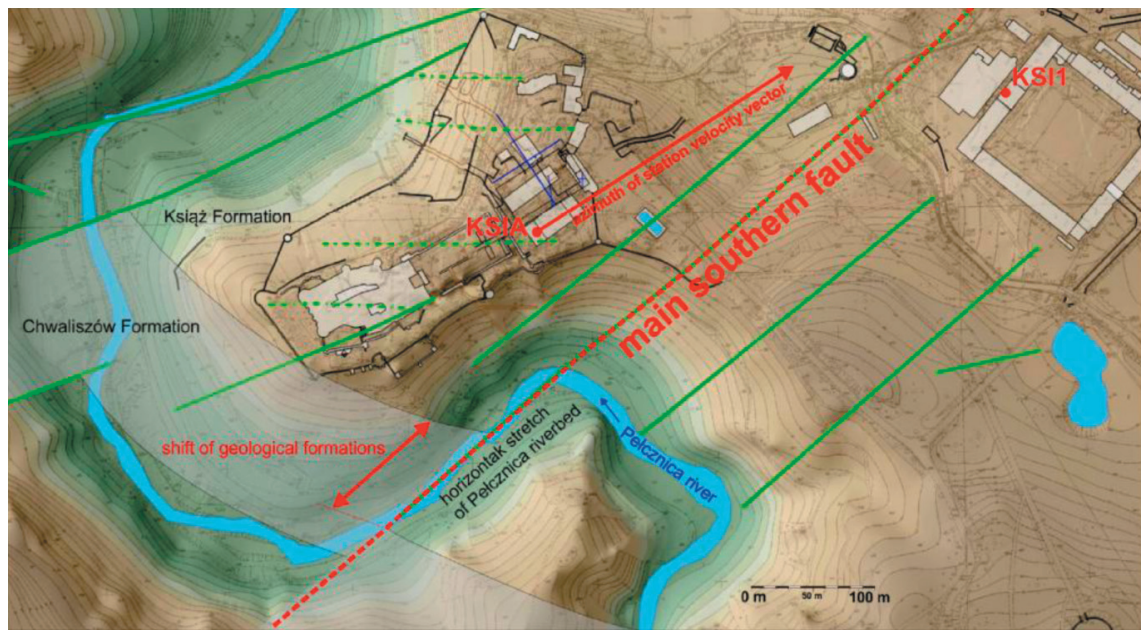

Fig. 17. Location of the new established GPS station KSI1 in relations to the existing station KSIA. Red dotted line represents the 'main southern fault', green dotted lines - indirect faults class 2 (Zdunek et al., 2014)

A methodology of the, determination of surface elevation changes with cartographic modelling in geographic information system (GIS) was described (Blachowski and Milczarek, 2014). The authors focused on two areas of Walbrzych Coal Basin around the city of Walbrzych in SW Poland and calculated mining terrain subsidence in the time span of 123 years (1886-2009). The elevation changes determined using interpolation methods and map algebra operations were compared with subsidence predicted by other authors, present-day orthophotomap of the area of Walbrzych and predictions made 
with Knothe method. The calculated subsidence reached $24 \mathrm{~m}$ and $36 \mathrm{~m}$ depending on the area analysed which corresponds to 0.2 and $0.3 \mathrm{~m} /$ year. The obtained results exhibit high correlation level with predictions from Knothe method - up to 0.9. A new deformation information system (DIS) that uses the modular structure concept to facilitate studies of mining-induced ground deformations was proposed (Blachowski et al., 2014). The system is to calculate various parameters that characterize the ground deformations in space and time. It integrates spatial and attributive data as well as interactive 3D geological and mine models. The system was verified for underground mines in Walbrzych in SW Poland. The results of 5 annual GPS observing campaigns carried out at the open pit mine Kozmin between 2008 and 2012 were presented and their usefulness for monitoring ground deformation were underlined (Baryla et al., 2014). The horizontal displacements not exceeding $\pm 8 \mathrm{~mm}$ with downward trend dominating were obtained. The authors concluded that the accuracy of displacements measured with GPS at the level of a few millimetres for each topocentric component and the accuracy of $\pm 3 \mathrm{~mm}$ of $3 \mathrm{D}$ position are possible to achieve.

Szczerbowski et al. (2011) analysed local changes of plumb line direction in Inowroclaw in central Poland on the basis of GPS, levelling and gravimetric surveys. The authors showed that the vertical deflection in a small flat area may change as a result of a local disturbance in mass distribution represented by the salt deposit. The total changes were found to be at the level of 1.7" at the distance of $4 \mathrm{~km}$. It has been stated that the mismodelled local quasigeoid can cause a maximum error of up to $11 \mathrm{~mm}$ in normal heights determined by GPS technique and therefore the increase of its resolution is necessary. A concept of a complete system of monitoring the magnitude and rate of rock mass surface deformations in planned sub-level caving mining operation in Kvannevann mine in Northern Norway (Fig. 18) was proposed (Blachowski et al., 2011). Specific

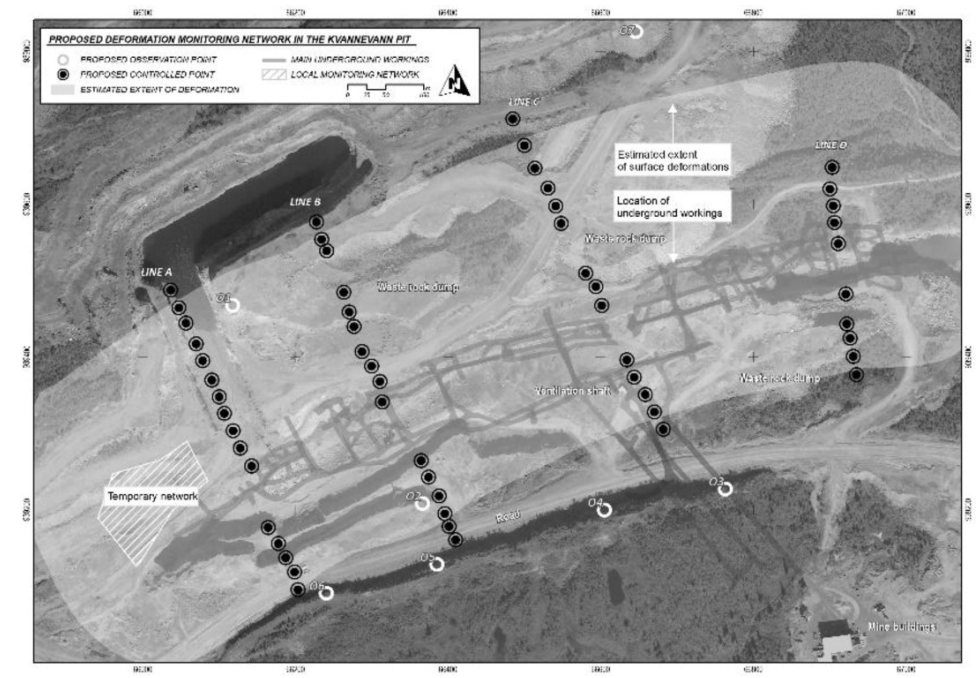

Fig. 18. Locations of controlled and observation points against the background of the production levels, estimated zone of deformation and surface features (Blachowski et al., 2011) 
conditions (e.g. location and climate) and expected deformations from numerical modelling made by the SINTEF Rock Engineering with Finite Element Method (FEM) were taken into account in the system. The authors proposed the accuracy of $\pm 2 \mathrm{~cm}$, the measurements taken at least twice a year, and locations of control points what would provide the sufficient set of data for further analyses.

The effects of monitoring of underground mining with sub-level caving system on the surrounding rock mass in a Kvannevann mine was described (Blachowski and Ellefmo, 2012). The authors implemented the surveying network for monitoring the displacements of control points and then numerically modelled the rock mass deformations with Finite Element Method. The network points were stabilised with $3 \mathrm{~m}$ long metal pipes to a depth and $2.5 \mathrm{~m}$ below the surface. The measurement campaigns were conducted in October and November 2011 at a 3 week interval. The analyses performed with FEM provided the information on general state of the rock mass in stages of large horizontal stresses undergoing mining.

Two new methods for transferring the heights from benchmarks, for which the levelling cannot be done, were proposed (Kuchmister et al., 2014). First one is based on the mono-photogrammetry with Direct Linear Transformation, and the second one - on the levelled laser beam that is emitted from the benchmark towards the levelling staff. The picture of staff graduation with the laser light spot taken with a digital camera is then processed to obtain the value of the reference. The first results show that the height can be determined with sub-millimetre accuracy.

Perski and Mroz (2012) showed the analysis of Persistent Scatterers Interferometry (PSI) for Sambia peninsula (Kaliningrad district of Russia) to give an answer whether the surface deformations result from tectonic processes related to the earthquake from 21 September 2004 or not. They processed the Synthetic Aperture Radar (SAR) data from ERS-1 and ERS-2 satellites from 1992-2001 for that region and obtained velocities of a few points with strictly linear trend. The analysis of 4 sets of PSI confirmed the tectonic origin of deformations with a few $\mathrm{mm} /$ year. Szostak-Chrzanowski and Chrzanowski (2014) used the GPS and satellite Interferometric Synthetic Aperture Radar (InSAR) data to monitor the separate ground subsidence due to gas withdrawal in the area of lower Mackenzie River Delta in Northern Canada from the total surface deformation resulting from natural causes such as permafrost degradation and post-glacial isostatic or tectonic uplift/subsidence of the area. They recommended the GPS technique to be a core of the monitoring scheme with a minimum of 25 monitoring points. The InSAR technique on the other hand will provide the information on the total accumulated surface subsidence. Cmielewski et al. (2012) described the instrument built by the Institute of Geodesy and Geoinformatics with the use of optoelectronic techniques. They showed that this instrument can measure the relative inclinations of engineering objects and inanimative nature phenomena with sub-millimetre accuracy. The authors showed, that the proposed device can be used for the determination of surface deformations caused by mining exploitation or hydrogeologic, geotechnical or constructional influences. 


\subsection{Tidal investigations}

The Borowa Gora Geodetic-Geophysical Observatory of IGiK is located $35 \mathrm{~km}$ north of Warsaw. In 2009 three LaCoste\&Romberg (LCR) gravimeters owned by the Institute of Geodesy and Cartography were upgraded with the LRFB-300 feedback system. The upgrade made it possible to record gravity data with $10 \mathrm{~nm} / \mathrm{s}^{2}$ readout resolution and near $2 \mathrm{~Hz}$ temporal resolution. The gravimetric tides are collected since the beginning of 2011 but unfortunately the first year of recording is complete only in $73 \%$. At the beginning of 2012 a set of Linux shell scripts has been developed to provide reliable and fully automatic tidal recordings (via Bluetooth) as well as automatic handling of any exceptional situations. The system runs with the LCR G1036 from the beginning of February 2012, and since then the completeness of the recording was improved to nearly $98-99 \%$. The first complete tidal analysis of 745 days of gravimetric recordings from 2012, 2013 and the beginning of 2014 was performed in early 2014 (Dykowski and Sekowski, 2014). Last classic calibration of the LCR G1036 on the gravimetric calibration baseline was performed in June 2011. During the period of consistent tidal recordings, calibration of the tidal gravimeter was performed 4 times with absolute gravimeters: 3 times with the A10-020 gravimeter of IGiK (Dykowski, 2012) and once with the FG5-230 gravimeter of WUT. Each time at least 1.5 days of simultaneous recordings of the LCR G1036 with an absolute gravimeter were performed. The estimated accuracy of the scale factor is close to $1 \%$. Last calibration of the LCR G1036 was performed at the end of 2013 (Dykowski and Sekowski, 2014). Tidal records from 745 days were used for the tidal adjustment. Due to the 8 day gap in December 2012 the data set was divided into two blocks. For the tidal analysis HW95 tidal catalogue was used as well as Wahr-Dehant inelastic Earth model. Results for the determined tidal components are presented for 5 minute (blue) and 1 hour data (dark blue) in Figure 19. The calculated

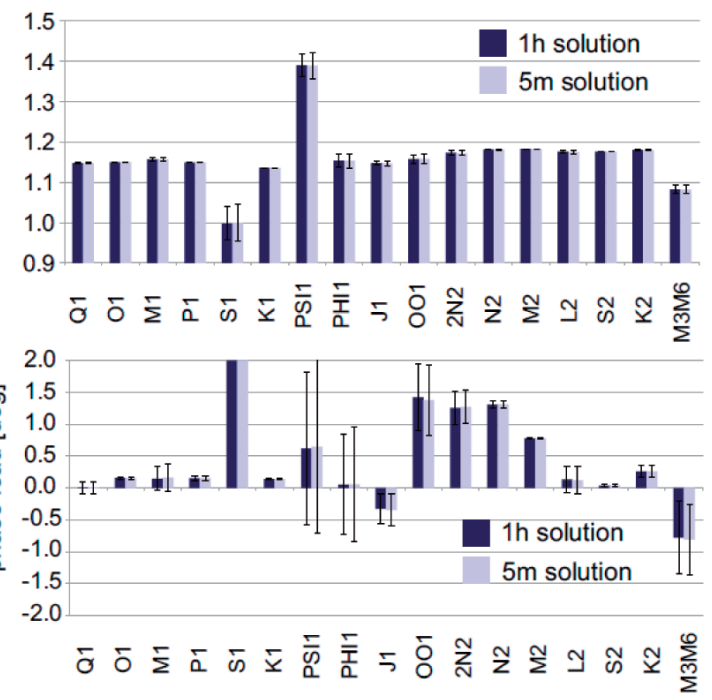

Fig. 19. Tidal factors (top) and phase leads (bottom) for the local model (Dykowski and Sekowski, 2014) 
standard deviations reach $2.9 \mathrm{~nm} / \mathrm{s}^{2}$ and $5.0 \mathrm{~nm} / \mathrm{s}^{2}$ for 1 hour and 5 minute solution, respectively as shown in Figure 19. The linear barometric coefficient calculated during the tidal adjustment is $-3.098 \mathrm{~nm} / \mathrm{s}^{2} / \mathrm{hPa}$ which is only slightly larger than the standard value of $-3.0 \mathrm{~nm} / \mathrm{s}^{2} / \mathrm{hPa}$. Nevertheless, it will cause a visible barometric correction difference only at significant local pressure changes.

\subsection{Astrometric observations}

Krynski and Zanimonskiy (2012) analysed the long-standing rotational time data series from 1986-2010 based on astrometric observations with the transit instrument at Borowa Gora Geodetic-Geophysical Observatory of IGiK. Spectral analysis performed showed a number of periodic signals (including a weekly term) in the time series investigated. The authors attempted to find a reliable interpretation of those signals. The numerical model of $(\mathrm{UT} 1-\mathrm{UTC})^{\mathrm{BG}}-(\mathrm{UT} 1-\mathrm{UTC})^{\mathrm{BIH}}$ at Borowa Gora was developed. The results were compared with the spectra taken from IERS data (Fig. 20).
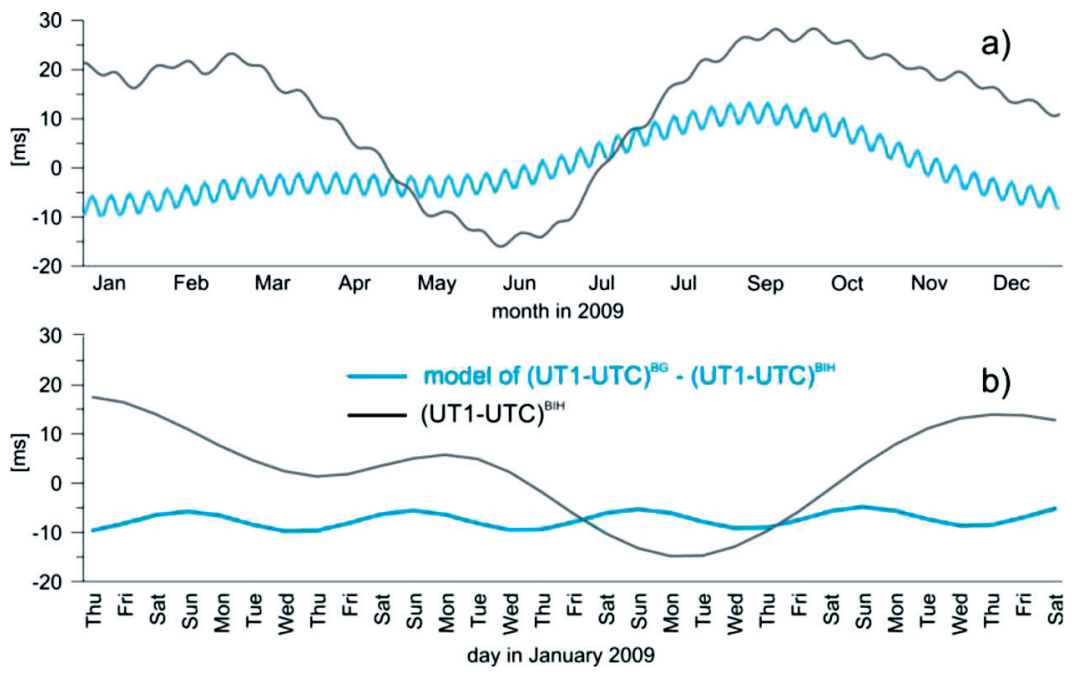

Fig. 20. Annual (a) and monthly (b) fragments of the time series of the model of $(\mathrm{UT} 1-\mathrm{UTC})^{\mathrm{BG}}-(\mathrm{UT} 1-\mathrm{UTC})^{\mathrm{BIH}}$ at Borowa Gora and $(\mathrm{UT} 1-\mathrm{UTC})^{\mathrm{BIH}}$ from EOP internet site (Krynski and Zanimonskiy, 2012)

\subsection{Precise levelling}

The first model of recent vertical movements in the area of Poland was developed by Wyrzykowski i in. 1987 using precise spirit (optical) levelling data from 1871-1882, 1926-1937, 1952-1956 and 1975-1977 campaigns of measuring the national vertical control. The newest model of recent vertical movements in the territory of Poland 
was developed by Kowalczyk in 2006 based on state precise spirit levelling data from 1974-1982 and 1997-2003 campaigns. After several years of GPS observations at about one hundred of permanent stations of the ASG-EUPOS network, a verification of those models became possible on the basis of independent (satellite) measurements. The model determined with the use of satellite data was compared with the models based on spirit levelling (Kontny and Bogusz, 2012) (Fig. 21).

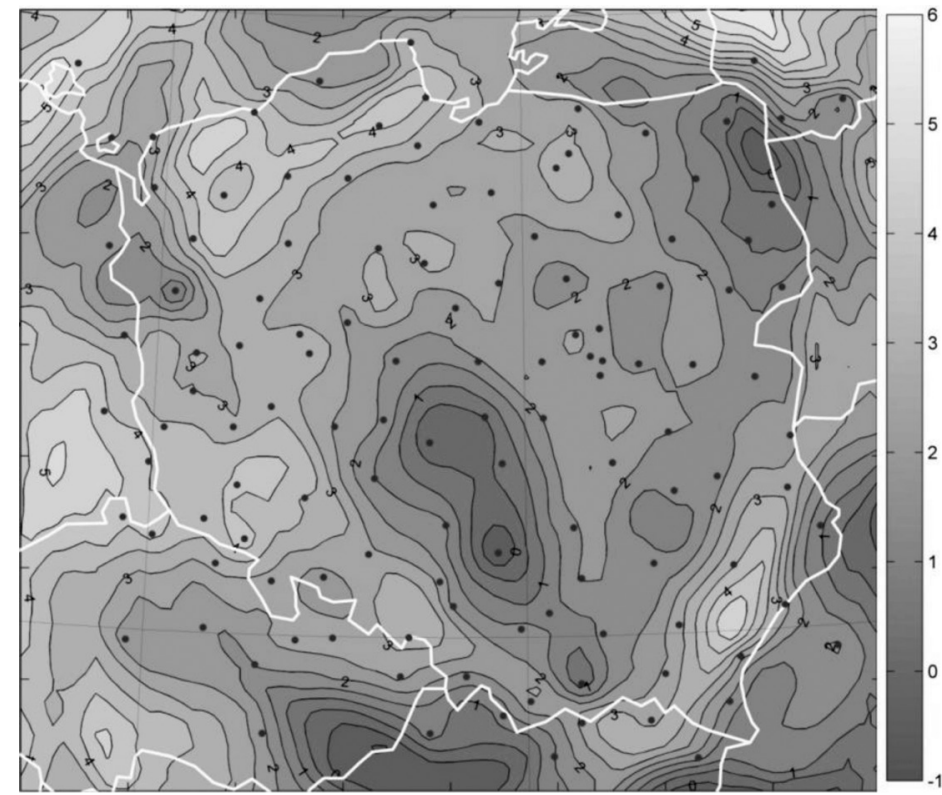

Fig. 21. Contour lines of the difference between the velocity model from the ASG-EUPOS and the model developed by Kowalczyk in 2006 [mm/yr] (Kontny and Bogusz, 2012)

Kowalczyk et al. (2011) collected data from four precise levelling campaigns conducted in Poland in 1926-1937, 1953-1955, 1974-1982 and 1997-2003 to standardize the levelling database structure, and presented the database schemes, relationships between different entities and examples of retrieving information with SQL queries. Kowalczyk and Rapinski (2012) described the methodology of common adjustment of the relative vertical crustal movements in Poland basing on three first order levelling campaigns. They unified the data from four campaigns, identified the common benchmarks and adjusted them in various scenarios. The authors further evaluated the usefulness of last three campaigns of precise levelling in Poland in terms of the development of vertical movement model concluding that the data from 1953-1955 and 1974-1982 campaigns should be of limited-trust (Kowalczyk and Rapinski, 2013). The adjusted data from three campaigns did not show much convergence of vertical movements for the nodes of double and triple levelling. The proposed hypothesis on mutual independence of residuals of triple levelling data turned out, however, to be correct. 


\section{Earth magnetic field}

Long-term research on secular variations of the geomagnetic field in Europe was continued at the Institute of Geodesy and Cartography, Warsaw. On the basis of the geomagnetic data obtained from the European observatories (INTERMAGNET) and from magnetic field stations, the chart of amplitudes changes of $Y$ magnetic field component (magnetic declination too) in Poland and the chart of time shift between Belsk Observatory - the Central Geophysical Observatory of the Institute of Geophysics of the Polish Academy of Sciences - and other measurement points records were processed. The results should show whether or not a special reduction procedure is needed to be applied. In 2010 and 2011, the new 17 field stations were operating in Poland (Fig. 22) and the records containing variations of $D$ (magnetic declination), $H$ (horizontal component of magnetic intensity vector) and $Z$ (vertical component of magnetic intensity vector) components provide a new material for analysis of the regional and local geomagnetic field changes.

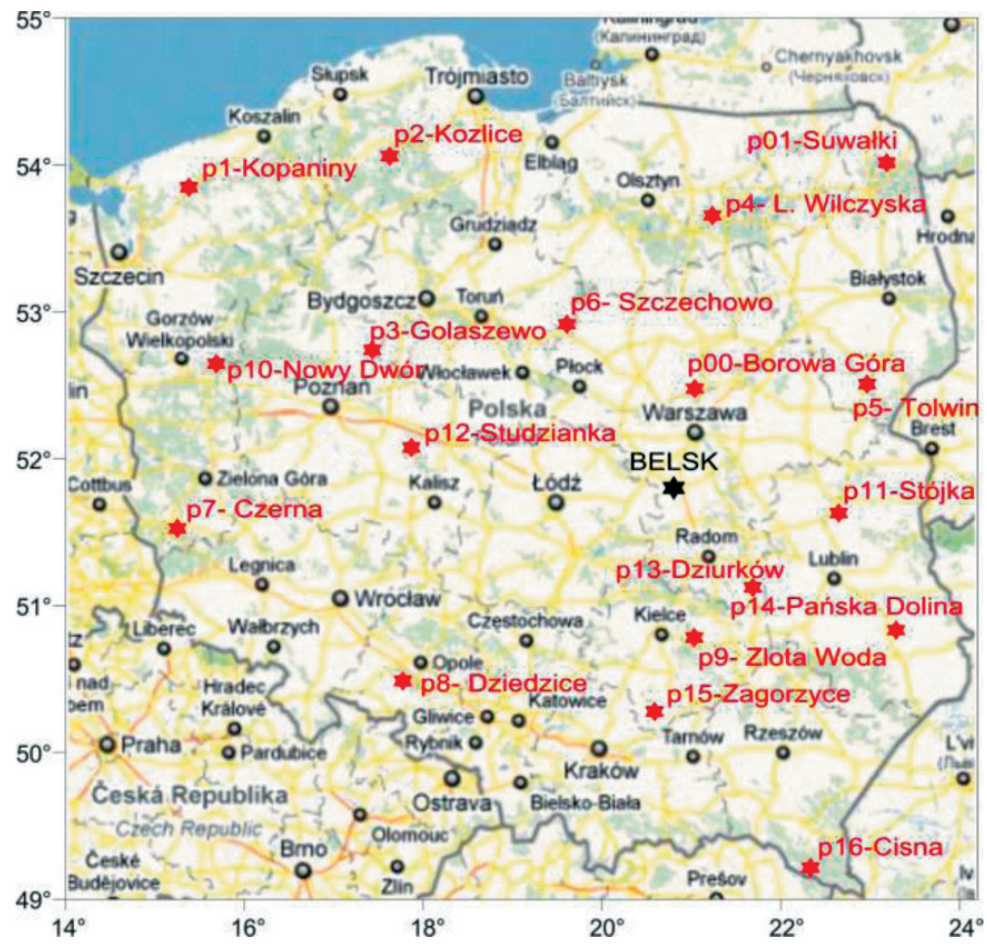

Fig. 22. The new variograph stations 2010-2011 in Poland (Welker, 2011)

The Fourier transformation was applied for the elaboration of the data from magnetic field stations in the same way as it has been done for magnetic observatory data. Figure 23 shows variations of declination recorded on all stations and in Belsk Observatory in a chosen period of 2011. 

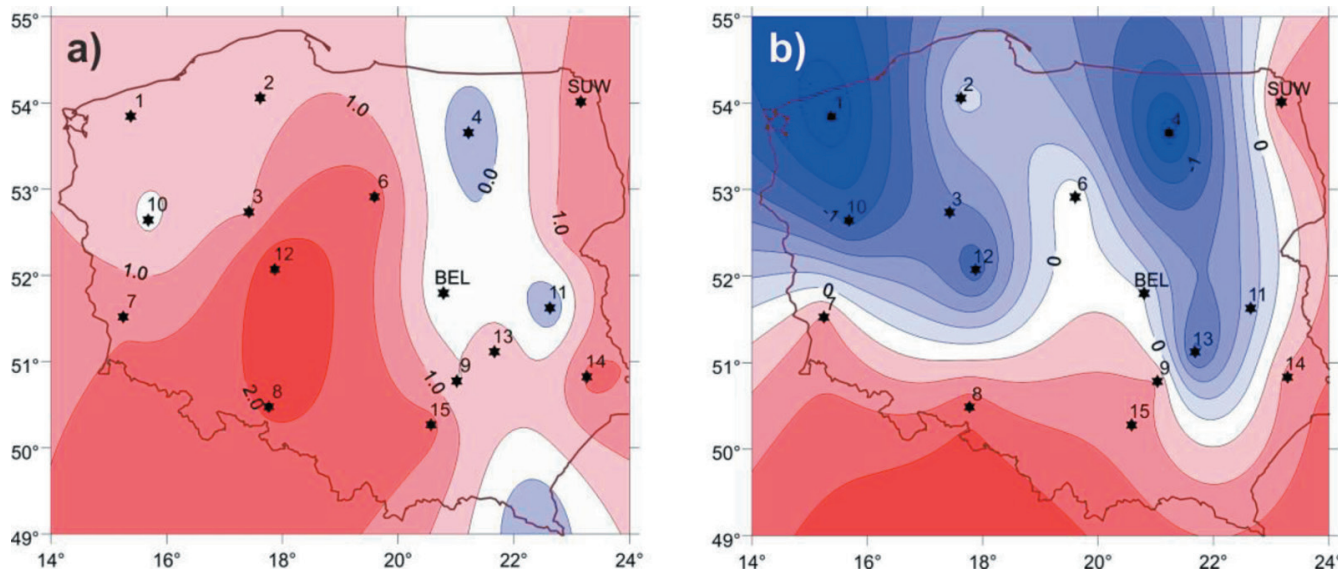

Fig. 23. Amplitude changes of declination reduced to Belsk Observatory from data of 2010 and 2011 - daily means a), and results of Fourier transformation b) (Welker, 2011)

Cross correlation obtained for observatories and stations data allows to show the chart of time shift between the records of $Y$ component at the investigated magnetic points and Belsk Observatory records (Fig. 24).

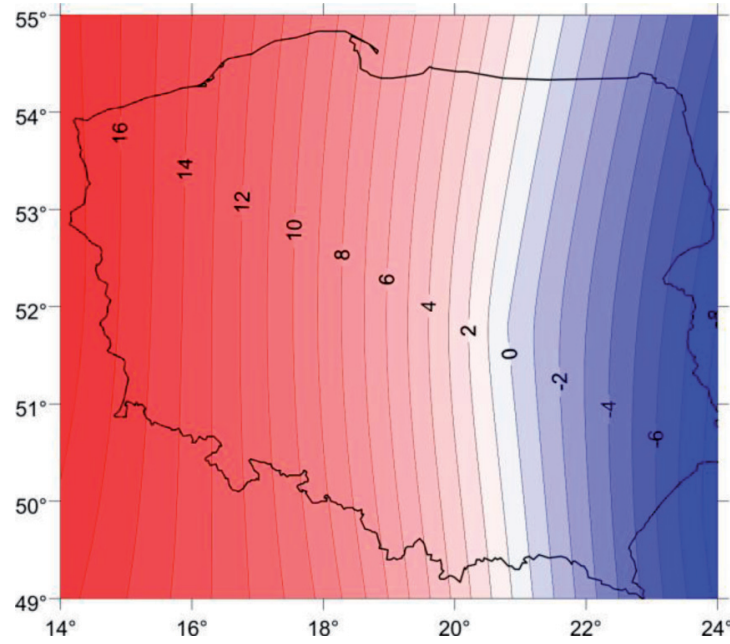

Fig. 24. Time shift between the records of the stations and others European observatories and Belsk Observatory records ( $Y$ component) (Welker, 2011)

Only declinations variations ( $Y$ variations) have a linear trend; the trend grows from East to West of Poland; the declination ( $Y$ component) can be predicted but only up to 3-5 years ahead. The changes of amplitudes of $D$ and $Y$ components in Poland are so small that they do not affect the reduction of magnetic measurements. Time corrections (from +6 to -15 minutes) should be applied when elaborating magnetic measurements data on continental scale in Europe. When processing magnetic data in Poland, those 
corrections can be neglected since they generate error smaller than measurement error (result of verification). It has been shown that the reduction of magnetic measurements from the points around central observatory $(100-200 \mathrm{~km})$ does not generate any error influencing declination accuracy. The magnetic measurements near Polish borders should be reduced to one of the closest observatories: Belsk, Hel, Hurbanovo, Niemegk or Lviv.

\section{Summary}

In this review an outline of researches concerning Earth rotation and geodynamics carried out by Polish scientific institutions from 2011 to 2014 is presented.

Research on Earth rotation in Poland focused on modelling the observed time variation of EOP as well as on the excitation studies based on available geophysical excitation data and models. An important part of modelling efforts concerned an application of the complex demodulation technique for analysis of diurnal and subdiurnal variations in Earth rotation. Such high frequency signal could be extracted from both the routine VLBI observations of EOP and the geophysical excitation series (AAM, OAM) with subdaily resolution. The earlier studies on the observed free oscillations in Earth rotation, the Chandler wobble and the free core nutation, have been continued in the reported period. The research on Earth rotation included also further improvements of the prediction techniques applied for the EOP data. Several publications have been devoted to the polar motion excitation studies. Particular attention was paid to the contribution of land hydrosphere to the excitation balance, which can be estimated either from the hydrology models or from the time variations of Earth gravity field detected by the satellite mission GRACE. Also the research on regional contributions to the excitation of polar motion has been continued, including the seasonal variations as well as the 14-month free Chandler wobble. The section on Earth rotation contains also a summary of the studies on the associated geodynamic phenomena like the geocenter motion which has not been investigated so far in Poland. Another subject, which is a continuation of earlier research, concerns the sea level change with particular attention paid to the role of ENSO phenomenon. The output of the sea level research consists of several publications including an extensive review of ENSO and selected environmental consequences (Niedzielski, 2014), as well as implementation at the University of Wroclaw of the near-real time system and service "Prognocean" for sea level prediction.

Due to serious failures of the laser module the Polish SLR station Borowiec did not operate in the considered time period, but the analyses on changes of other stations' positions were carried out as well as some attempts towards homogeneous reprocessing of GPS and SLR observations in the frame of GGOS. Several measurements and analyses concerning local geodynamics in the Southern Poland were done, especially on the geodynamic network of the Sudety Mts, established in 1996 and investigated until now. Separate research carried out in Ksiaz Observatory equipped with water-tube 
tiltmeter and with two GPS receivers was pointed out. The tidal investigation is currently performed in three observatories: the Borowa Gora Geodetic-Geophysical Observatory of IGiK, Jozefoslaw Astrogeodetic Observatory of WUT and Ksiaz Observatory of SRC. All of them observed tidal changes of gravity with spring gravimeters; additionally clinometric tides are observed in Ksiaz with hydrostatic clinometer. The results support the knowledge on elastic response of the Earth on the tidal forces. Astrometric observations made at Borowa Gora Observatory were re-processed to find and interpret periodic signals in time series and numerical model of (UT1 - UTC) ${ }^{\mathrm{BG}}-(\mathrm{UT} 1$ - UTC) $\mathrm{BIH}$ at Borowa Gora was developed. The model of recent vertical movements in the area of Poland, based on the precise levelling was developed and compared with the vertical velocities derived from the GPS observations at the ASG-EUPOS stations. Finally, the long-term research on secular variations of geomagnetic field in Europe was performed.

\section{Acknowledgements}

The content of the chapter was compiled with the use of the material provided by the authors as well as by Przemyslaw Dykowski, Pawel Lejba, Tomasz Niedzielski and Elzbieta Welker. Jan Krynski and Anna Klos are gratefully acknowledged for their valuable contributions to editing the chapter. The work of Aleksander Brzeziński, Wiesław Kosek and Jolanta Nastula on the report was supported by the Polish national science foundation NCN under grant No. DEC-2012/05/B/ST10/02132.

\section{References}

Alothman, A.O. and Schillak, S. (2014). Recent Results for the Arabian Plate Motion Using Satellite Laser Ranging Observations of Riyadh SLR Station to LAGEOS-1 and LAGEOS-2 Satellites. Arabian Journal For Science and Engineering, Vol. 39, No 1, 217-226, DOI:10.1007/s13369-013-0823-7.

Baryla, R., Paziewski, J., Wielgosz, P., Stepniak, K., and Krukowska, M. (2014). Accuracy assessment of the ground deformation monitoring with the use of GPS local network: open pit mine Koźmin case study. Acta Geodynamica et Geomaterialia, Vol. 11, No 4 (176), DOI:10.13168/AGG.2014.0013.

Birylo, M. and Nastula, J. (2012a). GRACE Signal Filtering as a Means of Determining Equivalent Water Thickness in Poland. Papers on Global Change, National IGBP-Global Change Committee PAS, Vol. 19 , pp. 33-42.

Birylo, M. and Nastula, J. (2012b). Local Equivalent Water Thickness Determination as a Source of Data For Flood Phenomenon Observation. Papers on Global Change, National IGBP - Global Change Committee PAS, Vol. 19, pp. 43-52.

Birylo, M. and Nastula, J. (2012c). GRACE Satellites usage for hydrological models determinations, Monography of University of Warmia and Mazury in Olsztyn, 4th PhD Seminar on Geodesy and Cartography, Olsztyn, Poland 9-10 June 2011, pp. 27-34.

Blachowski, J., Ellefmo, S. and Ludvigsen, E. (2011). Monitoring system for observations of rock mass deformations caused by sublevel caving mining system, Acta Geodynamica et Geomaterialia, Vol. 8, No 3(163), 335-344.

Blachowski, J. and Ellefmo, S. (2012). Numerical modelling of rock mass deformation in sublevel caving mining system. Acta Geodynamica et Geomaterialia, Vol. 9, No 3(167), 379-388. 
Blachowski, J. and Milczarek, W. (2014). Analysis of surface changes in the Walbrzych hard coal mining grounds (SW Poland) between 1886 and 2009. Geological Quarterly, Vol. 58, No 2, 353-367, DOI:10.7306/gq.1162.

Blachowski, J., Milczarek, W. and Stefaniak, P. (2014). Deformation information system for facilitating studies of mining-ground deformations, development, and applications. Natural Hazards And Earth System Sciences, Vol. 14, No 7, 1677-1689, DOI:10.5194/nhess-14-1677-2014.

Bogusz, J., Jarosiński, M. and Wnuk, K. (2011). Regional 2.5D model of deformations in Central Europe from GNSS observations: general assumptions of project. Reports on Geodesy, No 2 (91), 59-66.

Bogusz, J. and Figurski, M. (2012). Problem of intraplate velocity determination for geokinematic interpretations. Reports on Geodesy, Vol. 93, No 2, 25-33.

Bogusz, J., Figurski, M., Kontny, B. and Grzempowski, P. (2012a). Horizontal velocity field derived from EPN and ASG-EUPOS satellite data on the example of south-western part of Poland. Acta Geodynamica et Geomaterialia, Vol. 9, No 3(167), 349-357.

Bogusz, J., Figurski, M., Kontny, B. and Grzempowski, P. (2012b). Unmodeled effects in the horizontal velocity fields: ASG-EUPOS case study. Artificial Satellites, Vol. 47, No 2, 67-79, DOI:10.2478/ v10018-012-0014-x.

Bogusz, J., Kłos, A., Figurski, M., Jarosinski, M. and Kontny, B. (2013a). Investigation of the reliability of local strain analysis by the triangle modelling. Acta Geodynamica et Geomaterialia, Vol. 10, No 3(171), 293-305, DOI:10.13168/AGG.2013.0029.

Bogusz, J., Klos, A., Grzempowski, P. and Kontny, B. (2013b). Modelling velocity field in regular grid on the area of Poland on the basis of the velocities of European permanent stations. Pure and Applied Geophysics, Vol. 171, No 6(2014), 809-833, DOI:10.1007/s00024-013-0645-2.

Bogusz, J., Figursk,i M., Klos, A. and Araszkiewicz, A. (2014a). The use of locally weighted scatterplot smoothing in the analyses of GPS time series autocorrelations. Proceedings of the $14^{\text {th }}$ International Multidisciplinary Scientific GeoConference (SGEM 2014). ISSN 1314-2704, ISBN 978-619-7105-117, pp. 591-598, DOI:10.5593/sgem2014B22.

Bogusz, J., Figurski, M., Klos, A. and Araszkiewicz, A. (2014b). The goodness of fit of linear regression model in the determination of permanent stations' velocity. Proceedings of the $14^{\text {th }}$ International Multidisciplinary Scientific GeoConference (SGEM 2014). ISSN 1314-2704, ISBN 978-619-710511-7, pp. 513-520, DOI:10.5593/sgem2014B22.

Böhm, S., Brzezinski, A. and Schuh, H. (2012). Complex demodulation in VLBI estimation of high frequency Earth rotation components. Journal of Geodynamics, 62, 56-68, DOI: 10.1016/j.jog.2011.10.002.

Brzezinski, A. (2011): Diurnal excitation of Earth rotation estimated from recent geophysical models. Proc. Journées 2010 "Systèmes de référence spatio-temporels", (ed.) N. Capitaine, Observatoire de Paris, pp. 131-136.

Brzezinski, A. (2012). On estimation of the high frequency geophysical signals in Earth rotation by complex demodulation, Journal of Geodynamics, 62, 74-82, DOI:10.1016/j.jog.2012.01.008.

Brzezinski, A., Dobslaw, H., Dill, R. and Thomas, M. (2011). Geophysical excitation of the Chandler wobble revisited, Proc. IAG 2009 Scientific Assembly "Geodesy for Planet Earth". S. Kenyon et al. (eds.), IAG Symposia Series Vol. 136, Springer-Verlag Berlin Heidelberg, pp. 497-503, DOI 10.1007/9783-642-20338-1_60.

Brzezinski, A. and Böhm, S. (2012). Analysis of the high frequency components of Earth rotation demodulated from VLBI data, Proc. Journées 2011 "Systèmes de référence spatio-temporels". (eds.) H. Schuh, S. Böhm, T. Nilsson, and N. Capitaine, Observatoire de Paris, pp. 132-135.

Brzezinski, A. and Rajner, M. (2014). Estimation of the Chandler wobble parameters by the use of the Kalman deconvolution filter. Proc. Journées 2013 "Systèmes de référence spatio-temporels", (ed.) N. Capitaine, Observatoire de Paris, pp.189-192.

Brzezinski, A., Dobslaw, H. and Thomas, M. (2014).Atmospheric and Oceanic Excitation of the Free Core Nutation Estimated from Recent Geophysical Models. Proc. IAG 2011 Scientific Assembly "Earth on the Edge: Science for a Sustainable Planet", C. Rizos and P. Willis (eds.), IAG Symposia Vol. 139, pp. 461-466, DOI:10.1007/978-3-642-37222-3 61, Springer-Verlag Berlin Heidelberg 2014. 
Cacon, S., Kostak, B. and Makolski, K. (2012). Geodynamic effects detected in the Stolowe Góry mountains investigated originally for gravitational mass movements. Acta Geodynamica et Geomaterialia, Vol. 9 , No 4(168), 457-472.

Cmielewski, K., Kuchmister, J., Goluch, P. and Kowalski, K. (2012). The use of optoelectronic techniques in studies of relative displacements of rock mass. Acta Geodynamica et Geomaterialia, Vol. 9, No 3(167), 409-418.

Dykowski, P. (2012). Calibration of Relative Spring Gravimeters with the Use of the A10 Absolute Gravimeter, Symposium Gravity. Geoid and Height Systems GGHS2012, Venice, Italy, 9-12 October 2012.

Dykowski, P. and Sekowski, M. (2014). Tidal investigations at Borowa Gora Geodetic-Geophysical Observatory. EGU General Assembly 2014, held 27 April - 2 May, 2014 in Vienna, Austria, EGU201414048.

Grzempowski, P., Badura, J., Cacon, S., Kaplon, J., Rohm, W. and Przybylski, B. (2012). Geodynamics of south-eastern part of the Central European subsidence zone. Acta Geodynamica et Geomaterialia, Vol. 9, No 3(167), 359-369.

Kaczorowski, M. (2013). Unrecognized origin signals disturbing water-tubes tiltmeters measurements in geodynamic laboratory of SRC in Ksiaz. Acta Geodynamica et Geomaterialia, Vol. 10, No 3(171), 323-333, DOI:10.13168/AGG.2013.0031.

Kaczorowski, M. and Wojewoda, J. (2011). Neotectonic activity interpreted from a long water-tube tiltmeter record at the SRC Geodynamic Laboratory in Ksiaz Central Sudetes, SW Poland. Acta Geodynamica et Geomaterialia, Vol. 8, No 3(163), 249-261.

Kaplon, J., Kontny, B. Grzempowski, P., Schenk, V., Schenkova, Z., Balek, J. and Holesovsky, J. (2014). Geosud/Sudeten network GPS data reprocessing and horizontal site velocity estimation. Acta Geodynamica et Geomaterialia, Vol. 11, No 1(173), 65-75, DOI:10.13168/AGG.2013.0058.

Kasza, D., Kaczorowski, M., Zdunek, R. and Wronowski, R. (2014). The damages of Ksiaz castle architecture in relation to routes of recognized tectonic faults and indications of recent tectonic activity of Swiebodzice depression orogen - central Sudetes, SW Poland. Acta Geodynamica et Geomaterialia, Vol. 11, No 3(174), 225-234, DOI:10.13168/AGG.2014.0011.

Kolaczek, B., Pasnicka, M. and Nastula, J. (2012). Analysis of the geodetic residuals as differences between geodetic and sum of the atmospheric and oceanic excitation of polar motion. Proc. Journées 2011 "Systèmes de référence spatio-temporels", (eds.) H. Schuh, S. Böhm, T. Nilsson, and N. Capitaine, Observatoire de Paris, pp. 164-165.

Kontny, B. and Bogusz, J. (2012). Models of vertical movements of the Earth crust surface in the area of Poland derived from leveling and GNSS data. Acta Geodynamica et Geomaterialia, Vol. 9, No 3(167), 331-337.

Kosek, W. (2012). Future improvements in EOP prediction, Proc. IAG 2009 Scientific Assembly "Geodesy for Planet Earth”. S. Kenyon et al. (eds.), IAG Symposia Series Vol. 136, Springer-Verlag Berlin Heidelberg, pp. 513-520, DOI:10.1007/978-3-642-20338-1_62.

Kosek, W., Popinski, W. and Niedzielski, T. (2011a). Wavelet based comparison of high frequency oscillations in the geodetic and fluid excitation functions of polar motion, Proc. Journées 2010 "Systèmes de référence spatio-temporels", (ed.) N. Capitaine, Observatoire de Paris, pp. 168-171.

Kosek, W., Luzum, B., Kalarus, M., Wnek, A. and Zbylut, M. (2011b). Analysis of Pole Coordinate Data Predictions in the Earth Orientation Parameters Combination of Prediction Pilot Project. Artificial Satellites, 46, No 4/2011, DOI:10.2478/v10018-012-0006-x, pp. 139-150.

Kosek, W., Niedzielski, T., Popinski, W., Zbylut, M. and Wnek, A. (2013). Variable seasonal and subseasonal oscillations in sea level anomaly data and their impact on prediction accuracy, IAG Symposium Series Vol. 142, proceedings of the VIII Hotine Marussi Symposium..

Kosek, W., Wnek, A., Zbylut, M. and Popinski, W. (2014). Wavelet analysis of the Earth centre of mass time series determined by satellite techniques. Journal of Geodynamics, 80, 58-65, DOI: 10.1016/j. jog.2014.02.005. 
Kowalczyk, K., Bednarczyk, M. and Kowalczyk, A. (2011). Relational database of four precise levelling campaigns in Poland. $8^{\text {th }}$ International Conference Environmental Engineering, Vilnius, LITHUANIA, (eds.) D. Cygas; K.D. Froehner, Environmental Engineering, Vol. 1-3, pp. 1356-1361.

Kowalczyk, K. and Rapinski, J. (2012). Adjustment of vertical crustal movement network on the basis of last three leveling campaigns in Poland. Reports on Geodesy, Vol. 92, No 1, 123-134.

Kowalczyk, K. and Rapinski, J. (2013). Evaluation of levelling data for use in vertical crustal movements model in Poland. Acta Geodynamica et Geomaterialia, Vol. 10, No 4(172), 401-410, DOI:10.13168/ AGG.2013.0039.

Kowalczyk, K., Bogusz, J. and Figurski, M. (2014a). The analysis of the selected data from Polish Active Geodetic Network stations with the view on creating a model of vertical crustal movements. The $9^{\text {th }}$ International Conference "Environmental Engineering", Section: Technologies of Geodesy and Cadastre, 22-23 May 2014, Vilnius, Lithuania, eISSN 2029-7092 / eISBN 978-609-457-640-9, DOI:10.3846/enviro.2014.221.

Kowalczyk, K., Bogusz, J. and Figurski, M. (2014b). On the possibility of using GNSS data to model the vertical crustal movements. Proceedings of the $14^{\text {th }}$ International Multidisciplinary Scientific GeoConference (SGEM 2014), ISSN 1314-2704, ISBN 978-619-7105-11-7, pp. 567-574, DOI:10.5593/sgem2014B22.

Krynski, J. and Zanimonskiy, Y.M. (2012). Search for geodynamic signals in time series of astrometric observations. Reports on Geodesy,Vol. 92, No 1, 87-102.

Kuchmister, J., Cmielewski, K. and Goluch, P. (2014). The application of the optoelectronic technique of transferring heights from the recessed benchmarks in networks in the examination of rock mass deformation. Acta Geodynamica et Geomaterialia, Vol. 11, No 1(173), pp. 23-33, DOI:10.13168/ AGG.2013.0052.

Lejba, P. and Schillak, S. (2011). Determination of station positions and velocities from laser ranging observations to Ajisai, Starlette and Stella satellites. Advances in Space Research, Vol. 47, No 4, 654 662, DOI:10.1016/j.asr.2010.10.013.

Nastula, J. (2014). Gravimetric excitation function of polar motion from the GRACE RL05 solution, Proc. Journées 2013 "Systèmes de référence spatio-temporels". (ed.) N. Capitaine, Observatoire de Paris, pp. 208-211.

Nastula, J., Pasnicka, M. and Kolaczek, B. (2011a). Comparison of the geophysical excitations of polar motion from the period: 1980.0 - 2009.0, Acta Geophysica, 59(3), 561-577.

Nastula, J., Pasnicka, M., Kolaczek, B. and Salstein, D.A. (2011b). Comparison of the hydrological excitation functions HAM of polar motion for the period 1980.0-2007.0. Proc. Journées 2010 "Systèmes de référence spatio-temporels", (ed.) N. Capitaine, Observatoire de Paris, pp. 164-167.

Nastula J. and Salstein D.A. (2012): Regional Geophysical Excitation Functions of Polar Motion over Land Area, Proc. IAG 2009 Scientific Assembly "Geodesy for Planet Earth", S. Kenyon et al. (eds.), IAG Symposia Series Vol. 136, Springer-Verlag Berlin Heidelberg, 486-492, DOI:10.1007/978-3642-203338-1_59.

Nastula, J., Gross, R. and Salstein, D.A. (2012). Oceanic excitation of polar motion: Identification of specific oceanic areas important for polar motion excitation. Journal of Geodynamics, DOI:10.1016/j. jog.2012.012.002.

Nastula, J., Salstein, D.A. and Gross, R. (2014). Regional Multi-Fluid-Based Geophysical Excitation of Polar Motion. Proc. IAG 2011 Scientific Assembly "Earth on the Edge: Science for a Sustainable Planet", C. Rizos and P. Willis (eds.), IAG Symposia Vol. 139, pp. 467-472.

Niedzielski, T. (2011a). Is there any teleconnection between surface hydrology in Poland and El Niño/ Southern Oscillation? Pure and Applied Geophysics, 168, 871-886.

Niedzielski T., (2011b): Modelling and prediction of geospatial time series, In: W. Żyszkowska and W. Spallek (eds.), Główne problemy współczesnej kartografii 2011, Zastosowanie statystyki w GIS i kartografii, Uniwersytet Wrocławski, Wroclaw, pp. 73-82.

Niedzielski T., (2014): El Niño/Southern Oscillation and selected environmental consequences, Advances in Geophysics, 55, pp. 77-122. 
Niedzielski, T. and Kosek, W. (2011a).Minimum time span of TOPEX/Poseidon, Jason-1 and Jason-2 global altimeter data to detect a significant trend and acceleration in sea level change. Advances in Space Research, 47, 1248-1255.

Niedzielski, T. and Kosek, W. (2011b). Nonlinear sea level variations in the equatorial pacific due to ENSO, Proc. Journées 2010 "Systèmes de référence spatio-temporels". (ed.) N. Capitaine, Observatoire de Paris, pp. 217-218.

Niedzielski, T. and Kosek, W. (2012a). The statistical characteristics of altimetric sea level anomaly time series. Proc. IAG 2009 Scientific Assembly “Geodesy for Planet Earth”, S. Kenyon et al. (eds.), IAG Symposia Series Vol. 136, Springer-Verlag Berlin Heidelberg, 545-550, DOI:10.1007/978-3-64220338-1_66.

Niedzielski, T. and Kosek, W. (2012b). Prediction analysis of UT1-UTC time series by combination of the least-squares and multivariate autoregressive method. Proc. VII Hotine-Marussi Symposium on Mathematical Geodesy, N. Sneeuw, P. Novák, M. Crespi, F. Sansò (eds.), IAG Symposia Series Vol. 137, Springer-Verlag Berlin Heidelberg, pp. 153-157, DOI:10.1007/978-3-642-22078-4.

Niedzielski, T. and Miziński, B. (2013). Automated system for near-real time modelling and prediction of altimeter-derived sea level anomalies. Computers \& Geosciences, 58, 29-39.

Perski, Z. and Mroz, M. (2012). Natural recent earth surface displacements of Sambia Peninsula (Baltic Sea coast) studied with persistent scatterers interferometry. Acta Geodynamica et Geomaterialia, Vol. 9, No 1(165), 19-29.

Rajner, M. (2012). Earth crust deformation in Poland: modelling and its implication for positioning with satellite based geodetic techniques. Reports on Geodesy, Vol. 92, No 1, 37-46.

Rajner, M. and Liwosz, T. (2011). Studies of crustal deformation due to hydrological loading on GPS height estimates. Geodesy and Cartography, Vol. 60, No 2, 135-144, DOI:10.2478/v10277-012-0012-y.

Rajner, M., Olszak, T., Rogowski, J.B. and Walo, J. (2012). The influence of continental water storage on gravity rates estimates: case study using absolute gravity measurements from area of lower Silesia, Poland. Acta Geodynamica et Geomaterialia, Vol. 9, No 4(168), 449-455.

Rogowski, J.B. and Brzeziński, A. (2012). The celestial reference system and its role in the epoch of global geodetic technologies. Reports on Geodesy, Vol. 92. 163-174.

Seoane, L., Nastula, J., Bizouard, C. and Gambis, D. (2011). Hydrological excitation of polar motion derived from GRACE gravity field solutions. International Journal of Geophysics, 10, DOI:10.1155/2011/174396.

Szafranek K., Schillak S., (2012): Introduction to joint analysis of SLR and GNSS data, Reports on Geodesy, Vol. 92, No 1, 139-150.

Szafranek, K., Bogusz, J., Figurski, M., Sapota, M., Schillak, S. and Nykiel G. (2014). Determination of post-seismic decays from selected GNSS and SLR co-located sites. Proc. $14^{\text {th }}$ International Multidisciplinary Scientific GeoConference (SGEM 2014). ISSN 1314-2704, ISBN 978-619-710511-7, pp. 199-206, DOI:10.5593/sgem2014B22.

Szczerbowski, Z., Banasik, P. and Kudrys, J. (2011). Geological conditions and local changes of vertical deflections. Acta Geodynamica et Geomaterialia, Vol. 8, No 3(163), 263-271.

Szostak-Chrzanowsk, A. and Chrzanowski, A. (2014). Study of natural and man-induced ground deformation in Mackenzie delta region. Acta Geodynamica et Geomaterialia, Vol. 11, No 2(174), 117-123, DOI:10.13168/AGG.2013.0060.

Swierczynska, M., Niedzielski, T. and Kosek, W. (2014). Semiannual and annual oscillations of sea level and their impact on asymmetry between El Niño and La Niña episodes. Studia Geophysica et Geodaetica, 58, 302-325.

Tian, W., Brzezinski, A., Soffel, M.H., Gebauer, A., Schreiber, K.U. and Klügel, T. (2011). The interpretation of high frequency signals in the G-ring laser gyroscope.Proc. Journées 2010 "Systèmes de référence spatio-temporels", (ed.) N. Capitaine, Observatoire de Paris, pp. 225-226.

Welker, E. (2011). The influence of variantions of the Earth magnetic field intensity on the elaboration of geomagnetic observations in Poland. Geoinformation Issues, Vol. 3, No 1(3), 19-37. 
Zdunek, R. (2012). Permanent GPS station in Ksiaz Geodynamic Laboratory for supporting investigations of neo-tectonic motions in the Ksiaz massif. Acta Geodynamica et Geomaterialia, Vol. 9, No 3(167), 371-377.

Zdunek, R., Kaczorowski, M., Kasza, D. and Wronowski, R. (2014). Preliminary interpretation of determined movements of KSIA and KSI1 GPS stations in context of collected information about Swiebodzice trough tectonics. Acta Geodynamica et Geomaterialia, Vol. 11, No 4(176), 305-315, DOI: 10.13168/AGG.2014.0016 